\title{
PRESIDENTES Y ORQUESTADORES: LA GOBERNANZA DE LA PANDEMIA DE COVID-19 EN LAS AMÉRICAS
}

\author{
PRESIDENTS AND ORCHESTRATORS: THE GOVERNANCE \\ OF THE COVID-19 PANDEMIC IN THE AMERICAS
}

\section{PRÉSIDENTS ET ORCHESTRATEURS: LA GOUVERNANCE DE LA PANDÉMIE DE COVID-19 DANS LES AMÉRIQUES}

Thomas Legler

Universidad Iberoamericana thomas.legler@ibero.mx

Resumen: Este artículo se propone analizar tendencias contradictorias en la gobernanza hemisférica y regional de la pandemia de Covid-19. Basado en un extenso ejercicio de mapeo de las dinámicas institucionales de cooperación, en él se describe una mezcla de tendencias de gobernanza conflictivas, tanto negativas como positivas, así como desarticuladas y colaborativas. El autor sostiene que la gobernanza de la pandemia en el hemisferio surge de la convergencia histórica y de la vinculación de dos pautas de gobernanza en la seguridad sanitaria, en las últimas décadas: el interpresidencialismo y la orquestación de las organizaciones regionales. Aun si dio la impresión de que las respuestas fueron nacionales e individualizadas y de que resaltaron las disfuncionalidades de los esquemas de gobernanza existentes, observamos una efervescencia de formas heterogéneas de cooperación y creación de instituciones hemisféricas y regionales contra el virus y sus consecuencias más amplias. Gracias a su capacidad de resistencia y organización, varios organismos regionales formales y bancos de desarrollo lograron compensar al menos parcialmente las pautas perturbadoras del interpresidencialismo patológico a través de sus funciones como orquestadores de gobernanza. Sobre la base de sus hallazgos, en el artículo se hace un llamado al intercambio fecundo de ideas entre el regionalismo comparativo, el institucionalismo neoliberal y los estudios de gobernanza global, así como la construcción de un interpresidencialismo en red para contrarrestar los peores impulsos de los jefes de Estado y de gobierno. 
Palabras clave: gobernanza de la salud; organizaciones regionales; América Latina; orquestación; interpresidencialismo; Covid-19.

\section{Traducción de Rafael Segovia, GC Idiomas}

ABSTRACT: This article seeks to interpret and explain contradictory trends in the hemispheric and regional governance of the Covid-19 pandemic. Based on an extensive mapping exercise of cooperation and institutional trends, this article depicts a mix of conflicting governance tendencies, both negative and positive, as well as disarticulated and collaborative. The author argues that the existing governance of the pandemic in the hemisphere stems from the historical convergence and intertwining of two macro governance patterns in health security in recent decades: inter-presidentialism and orchestration by regional organizations. Despite the impression of individualized national responses and governance dysfunctionality, a veritable effervescence of heterogeneous hemispheric and regional forms of cooperation and institution-building has occurred against the virus and its broader fallout. Thanks to their resilience and organizational capacity, various formal regional organizations and development banks managed to offset at least partially disturbing trends in pathological interpresidentialism through their roles as governance orchestrators. On the basis of its findings, the article calls for theoretical cross-fertilization among comparative regionalism, neoliberal institutionalism, and global governance studies, as well the construction of networked inter-presidentialism in order to counterbalance the worst impulses of presidents.

Keywords: health governance; regional organizations; Americas,

Latin America; orchestration; inter-presidentialism; Covid-19.

RÉsumé : Cet article propose une analyse des tendances contradictoires de la gouvernance hémisphérique et régionale de la pandémie de Covid-19. Basé sur un vaste exercice de cartographie des dynamiques institutionnelles de coopération, cet article dépeint une combinaison de tendances de gouvernance conflictuelles, à la fois négatives et positives, désarticulées et collaboratives. L'auteur défend que la gouvernance de la pandémie dans l'hémisphère résulte de la convergence historique et de l'entrelacement de deux tendances de gouvernance en matière de sécurité sanitaire au cours des dernières décennies: l'inter-présidentialisme et l'orchestration due aux organisations régionales. Malgré l'impression de la prépondérance des réponses nationales individualisées et 
bien que ressortent les dysfonctionnements des modes de gouvernance existants, nous observons une effervescence de formes hétérogènes de coopération et la création d'institutions hémisphériques et regionales dans la lutte contre le virus et ses répercussions multidimensionnelles. Grâce à leur capacité de résilience et d'organisation, divers organismes régionaux formels ainsi que des banques de développement ont réussi à compenser au moins partiellement les tendances perturbatrices de l'inter-présidentialisme pathologique grâce à leur rôle d'orchestrateurs de la gouvernance. Sur la base de ses conclusions, l'article appelle à un échange d'idées fécond entre le régionalisme comparatif, l'institutionnalisme néolibéral et les études de gouvernance mondiale, ainsi qu'à la construction d'un inter-présidentialisme en réseau afin de contrebalancer les pires impulsions des chefs d'Etat et de gouvernement.

Mots clefs: gouvernance de la santé ; organisations régionales ;

Amériques ; Amérique latine ; orchestration ; inter-présidentialisme ; Covid-19.

Traducción de Rafael Segovia, GC Idiomas

Fecha de recepción: enero de 2021.

Fecha de aceptación: febrero de 2021. 


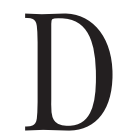
esde el año pasado, ha florecido un debate académico muy animado en torno a interpretaciones contrapuestas de la gobernanza hemisférica y regional de la pandemia de Covid-19 en las Américas. ${ }^{1}$ Para un grupo de autores, el patrón de respuesta más frecuente de los Estados a la pandemia ha sido atomizado y desarticulado. Según Raúl Bernal-Me$\mathrm{za}$, las tendencias unilaterales y nacionalistas han anunciado "el regreso del Leviatán" y reflejan una pauta de comportamiento centrada en el Estado, o "sálvese quien pueda". ${ }^{2}$ Carlos Malamud se lamenta de lo que ha llamado el surgimiento del "egoísmo nacional, el egoísmo Covid y el populismo Covid" en un contexto de fragmentación regional. ${ }^{3}$ Por su parte, Pia Riggirozzi afirma que lo nacional ha sustituido a lo regional, lo que implica un retorno a la preponderancia de las fronteras nacionales. ${ }^{4}$

Riggirozzi también observa que la pandemia estalló en un momento en el que hubo una "clara erosión del pensamiento y la práctica de la gobernanza regional sanitaria". ${ }^{5}$ Jerónimo Ríos Sierra sostiene que la Covid-19 ha amplificado la "desestructuración regional" de América Latina y que

${ }^{1}$ El autor agradece sinceramente a Juan Cruz Olmeda, Élodie Brun, los dos revisores anónimos y Jessy Quezada por su apoyo en la preparación de este artículo.

${ }^{2}$ Raúl Bernal-Meza, “¿Orden regulado por la anarquía? Asistimos al retorno del Leviatán”, Clarín, 19 de marzo de 2020; Carlos Malamud y Rogelio Núñez, "AMLO y Bolsonaro ante el coronavirus: tan distintos y, sin embargo, tan iguales", Real Instituto Elcano, 26 de marzo de 2020; Carlos Malamud, "Coordinación regional frente al Covid-19 en América Latina", Real Instituto Elcano, 3 de junio de 2020.

${ }^{3}$ Carlos Malamud, "Latinoamérica al son de la COVID-19", La Verdad, 26 de julio de 2020.

${ }^{4}$ Pía Riggirozzi, "Coronavirus y el desafío para la gobernanza regional en América Latina”, Análisis 12/2020, Fundación Carolina, 30 de marzo de 2020, 7-8.

${ }^{5}$ Ibid., p. 2. 
las respuestas regionales han sido anémicas o inexistentes, con lo que se ha cuestionado la utilidad de los procesos de integración regional. ${ }^{6}$ Según Oliver Stuenkel, ha habido un colapso de la cooperación y la coordinación regionales, en el que muchos presidentes latinoamericanos están más interesados en culpar o en involucrarse en política mezquina que en trabajar con sus pares contra el virus. ${ }^{7}$ Gian Luca Gardini añade que la gama de organizaciones regionales latinoamericanas no ha podido adoptar medidas significativas ni apoyar a sus miembros con acciones o recursos importantes. ${ }^{8}$

Otra lectura, más optimista, hace hincapié en el hecho de que las y los especialistas médicos, científicos y directivos han participado en iniciativas significativas de cooperación y que el multilateralismo técnico-científico tiene el potencial de superar las diferencias políticas, ideológicas e interpersonales entre líderes y países, y de impulsar la restauración de los procesos de integración en las Américas. En consecuencia, organizaciones como la Organización Panamericana de la Salud (ops) o la Comisión Económica para América Latina y el Caribe (Cepal) aprovechan la percepción de su relativa neutralidad, de su impermeabilidad política e ideológica, así como de su reputación de excelencia técnica y científica, lo que les permite sanar las divisiones entre los países de la región en favor de la causa común que es la lucha contra la

${ }^{6}$ Jerónimo Ríos Sierra, "Una aproximación (geo)política a la crisis de la Covid-19 en América Latina”, Journal of Latin American Geography, vol. 19, núm. 3, 2020, pp. 194-201; Jerónimo Ríos Sierra, "La inexistente respuesta regional a la Covid-19 en América Latina", Geopolítica(s). Revista de Estudios sobre espacio y poder, vol. 11, núm. especial, 2020, pp. 209-222; Jerónimo Ríos Sierra, "Latin America's Weak Regionalism in the Face of Covid-19," Global Americans, 23 de septiembre de 2020.

7 Oliver Stuenkel, "The Peril of a Rudderless Continent", Americas Quarterly, 29 de octubre de 2020.

${ }^{8}$ Gian Luca Gardini, "Covid-19, la movilización y solidaridad de la UE, y el regionalismo comparado", en Gian Luca Gardini (coord.), el Mundo antes y después del COVID-19, Salamanca, Instituto Europeo de Estudios Internacionales, 2020, pp. 124-128. 
Covid-19. ${ }^{9}$ Sebastien Dubé sostiene que estas organizaciones técnicas podrían convertirse en los precursores de una quinta ola emergente de regionalismo, similar a la teoría del funcionalismo de David Mitrany. ${ }^{10}$

Un tercer grupo de autores reconoce un conjunto más diverso de respuestas de gobernanza a la pandemia en todo el hemisferio occidental, en lugar de un patrón general único. Como observan Mónica Hirst y Bernabé Malacalza, aunque abundan los problemas de cooperación, el panorama no ha sido tan sombrío o tan uniforme como la interpretación de "sálvese quien pueda" indicada anteriormente. Además de los encomiables esfuerzos de la ops, destacan las iniciativas de salud pública emprendidas por la Comunidad del Caribe (Caricom) y el Sistema de Integración Centroamericano (Sica), ${ }^{11}$ además de otras acciones modestas bajo los auspicios del Mercado Común del Sur (Mercosur) y del Programa Iberoamericano para el Fortalecimiento de la Cooperación Sur-Sur (PIFCSs), entre otros. ${ }^{12}$

¿Qué está sucediendo en términos de la gobernanza hemisférica y regional de la pandemia de Covid-19 en las Américas y cómo se explica? ¿Pueden reconciliarse estas interpretaciones contradictorias? Sobre la base de un extenso ejercicio de

${ }^{9}$ Gilberto Rodrigues y Alberto Kleiman, “Covid-19: ¿una nueva oportunidad para el multilateralismo?”, Foreign Affairs Latinoamérica, vol. 20, núm. 3, 2020, pp. 36-43.

${ }^{10}$ Sébastien Dubé, "A Supposed Fifth Wave of Latin American Regionalism and Human Needs", Regions and Cohesion, vol. 10, núm. 3, 2020, pp. 58-71. Sobre las cuatro olas históricas del regionalismo latinoamericano en el siglo xx, véase Olivier Dabène, "La cuarta ola de regionalismo", en Carlos Quenan, Sébastien Velut, y Eric Jourcin (coords.), Los desafíos del desarrollo en América Latina, París, Institut des Amériques, 2014, pp. 64-95.

${ }^{11}$ Sobre la Caricom y el Sica, véase el articulo de Kevin Parthenay en este dossier.

12 Mónica Hirst y Bernabé Malacalza, “¿Podrá reinventarse el multilateralismo? El orden internacional y el coronavirus", Nueva Sociedad, núm. 287, 2020, pp. 35-48. Véase también Paulo M. Buss y Sebastián Tobar, "Multilateralismo y COVID-19 en América Latina”, Revista Chilena de Salud Pública, núm. especial, 2020, pp. 123-135. 
mapeo de las dinámicas institucionales de cooperación, sostengo que los acontecimientos en el hemisferio occidental revelan una mezcla de tendencias de gobernanza contradictorias, tanto negativas como positivas, a la vez desarticuladas y colaborativas. Yo sostengo que la gobernanza de la pandemia en las Américas, tal como opera en la actualidad, se deriva de la convergencia histórica y el entrelazamiento en las últimas décadas de dos macrotendencias de gobernanza en área temática de la seguridad sanitaria: el interpresidencialismo y la orquestación de las organizaciones regionales. A pesar de una serie de incidentes perturbadores que alimentan la impresión según la cual las respuestas a la pandemia son esencialmente nacionales e individualizadas y que la gobernanza en las Américas es disfuncional, ha habido una efervescencia de formas heterogéneas de cooperación hemisférica y regional, y de creación de instituciones contra el virus y sus consecuencias más amplias. Gracias a su resiliencia y capacidad de organización, los organismos regionales formales y los bancos de desarrollo lograron compensar, al menos parcialmente, las tendencias perturbadoras de lo que puede denominarse interpresidencialismo patológico, mediante su propio papel como orquestadores de la gobernanza.

El capítulo se divide en tres partes. En primer lugar, en la siguiente sección se esboza el desarrollo de la arquitectura de la gobernanza hemisférica y regional para la seguridad sanitaria antes del inicio de la pandemia, mediante la yuxtaposición de los impulsos de la gobernanza interpresidencialista e indirecta. En segundo lugar, se examinan las tendencias contradictorias en la cooperación y la construcción de instituciones de la lucha contra la pandemia y cómo están vinculadas al nexo entre el interpresidencialismo y la gobernanza indirecta. Por último, en la conclusión exploro las implicaciones de este análisis, a saber, la cuestión de cómo controlar el papel potencialmente perjudicial de los presidentes en los procesos de gobernanza hemisférica y regional. 
Arquitectura de LA GOBERNANZA DE LA SEGURIDAD SANITARIA EN LAS AMÉRICAS ANTES DE LA PANDEMIA DE COVID-19

La construcción de la arquitectura de seguridad sanitaria en las Américas antes de la pandemia de Covid-19 responde a la yuxtaposición histórica de dos macrotendencias de gobernanza. ${ }^{13}$ Por un lado, la Organización Mundial de la Salud (oms) y la ops promovieron la consolidación del régimen mundial de seguridad sanitaria en las Américas mediante la orquestación y la transferencia de gobernanza. Por el otro, bajo el impulso del interpresidencialismo, los proyectos de regionalismo en todo el hemisferio intentaron en varias ocasiones regionalizar la seguridad sanitaria mediante la creación de sus propios mecanismos institucionales para contrarrestar la amenaza de las enfermedades contagiosas. Como explicaré a continuación, este aparato institucional mostró signos tan alentadores como preocupantes en cuanto a su capacidad general para proteger a los Estados y a la ciudadanía de las emergencias de salud pública de interés internacional (PHEIC, por sus siglas en inglés). Con el beneficio de la retrospectiva, podemos ver que, en vísperas del brote del coronavirus, las organizaciones e instituciones informales regionales de salud pública y de bajo costo asociadas con la iniciativa interpresidencial eran el eslabón potencialmente débil en esta arquitectura.

Tras el riesgo de pandemia mundial presentado por el síndrome respiratorio agudo severo (sARs), los Estados miem-

${ }^{13}$ La gobernanza regional y mundial se define aquí como la resolución o gestión de problemas regionales y mundiales específicos mediante la creación de distintas esferas de autoridad regionales y mundiales, cada una de las cuales está acompañada por un conjunto de actores y arquitectura institucional correspondiente y está imbuida de formas directas e indirectas de poder. La arquitectura de gobernanza puede definirse como “...el sistema general de instituciones públicas y privadas que son válidas o están activas en una esfera temática determinada de la política mundial”. Frank Biermann, Philipp Pattberg, Harro van Asselt y Fariborz Zelli, "The Fragmentation of Global Governance Architectures: A Framework for Analysis", Global Environmental Politics, vol. 9, núm. 4, 2009, p. 15. 
bros de la oms aprobaron en 2005 un nuevo Reglamento Sanitario Internacional (RSI) que fortaleció a la oms como piedra angular del régimen mundial de seguridad sanitaria. ${ }^{14}$ El Rs codificó la esencia y el propósito de este régimen: "[...] prevenir la propagación internacional de enfermedades, proteger contra esa propagación, controlarla y darle una respuesta de salud pública proporcionada y restringida a los riesgos para la salud pública y evitando al mismo tiempo las interferencias innecesarias con el tráfico y el comercio internacionales". ${ }^{15}$ Como observa Lorna Weir, la seguridad sanitaria mundial consta de un aparato de gobernanza particular para la vigilancia, detección y respuesta rápida de enfermedades que "[...] combine actores humanos, objetos, declaraciones y dispositivos técnicos en redes formadas a través de conocimientos expertos autorizados". 16

Gracias al RSI, tanto la OMs como su socio regional, la ops, adquirieron nuevas facultades delegadas por los Estados miembros en relación con la preparación ante las pandemias y la vigilancia de las enfermedades, las medidas de mitigación y el desarrollo de medicamentos y vacunas en caso de producirse una PHEIC. Estas atribuciones permitieron a la oms y a la ops servir potencialmente como orquestadores de la gobernanza de seguridad sanitaria, así como agentes de transferencia de la gobernanza. La orquestación es un modo de gobernanza en el que las organizaciones intergubernamen-

${ }^{14}$ Respecto al régimen mundial de seguridad sanitaria, véase Steven J. Hoffman, "The Evolution, Etiology and Eventualities of the Global Health Security Regime”, Health Policy and Planning, vol. 25, núm. 6, 2010, pp. 510-522; Andrew Lakoff, "Two Regimes of Global Health", Humanity: An International Journal of Human Rights Humanitarianism and Development, vol. 1, núm. 1, 2010, pp. 59-79.

15 Organización Mundial de la Salud, oms, Reglamento Sanitario Internacional, Ginebra, 2005, p. vii.

${ }^{16}$ Lorna Weir, "Inventing Global Health Security, 1994-2005”, en Simon Rushton y Jeremy Youde (eds.) Routledge Handbook of Global Health Security, Londres, Routledge, 2014, p. 18. 
tales (OI) "[...] reclutan a actores intermediarios voluntariamente, proporcionándoles apoyo ideacional y material, para dirigirse a actores objetivo para la consecución de los objetivos de gobernanza de las oI". ${ }^{17}$ Los intermediarios podrían incluir organizaciones regionales (OR), bancos y agencias especializadas, comunidades de expertos/as, organizaciones no gubernamentales (ONG) y asociaciones público-privadas. De acuerdo con Stefano Palestini, las organizaciones orquestan a los intermediarios por medio de al menos tres mecanismos: mediación, configuración de la agenda y asistencia. ${ }^{18}$

La transferencia de la gobernanza se refiere a las actividades en las que " [...] las organizaciones regionales prescriben explícitamente y/o promueven y protegen intencional y activamente la construcción, modificación y respeto de las instituciones de gobernanza en sus Estados miembros o en terceros países". ${ }^{19}$ Tanya Börzel y Vera Van Hüllen conciben la transferencia de la gobernanza desde un enfoque institucional: como una serie de iniciativas de las or para fomentar, fortalecer o proteger las instituciones nacionales de gobernanza. A la luz de la experiencia organizativa en la lucha contra el coronavirus, amplío el concepto para incluir también la entrega de bienes materiales tangibles, así como la transmi-

${ }^{17}$ Kenneth W. Abbott, Philipp Genschel, Duncan Snidal y Bernhard Zangl, International Organizations as Orchestrators, Cambridge, Cambridge University Press, 2015, p. 3. Véase también Kenneth W. Abbott, Philipp Genschel, Duncan Snidal y Bernhard Zangl, "Two Logics of Indirect Governance: Delegation and Orchestration", British Journal of Political Science, vol. 46, núm. 4, 2015, pp. 719-729; Tine Hanrieder, "WHO Orchestrates?", en Kenneth W. Abbott et al. (eds.), International Organizations as Orchestrators, Cambridge, Cambridge University Press, 2015, pp. 191-213.

${ }^{18}$ Stefano Palestini, "Orchestrating Regionalism: The Interamerican Development Bank and the Central American Electric System", Review of Policy Research, versión en línea, 2020, pp. 1-18.

${ }^{19}$ Tanja A. Börzel y Vera van Hüllen, "Towards a Global Script? Governance Transfer by Regional Organizations", en Tanja A. Börzel y Vera van Hüllen (eds.), Governance Transfer by Regional Organizations, Basingstoke, Palgrave Macmillan, 2015, p. 5. 
sión de conocimientos y capacidades de gobernanza de las or a los Estados y a sus poblaciones. Este puente entre la orquestación y la transferencia de la gobernanza permite una mayor apreciación de las posibles contribuciones en materia de gobernanza de las organizaciones hemisféricas y regionales como orquestadoras en el contexto de la pandemia. Es decir, no sólo coordinan las iniciativas de las redes de actores, sino que, ya sea individualmente o al unísono con aquellas, también otorgan beneficios institucionales y materiales concretos, conocimiento y expertise a los beneficiarios seleccionados.

Nacida en 1902, incluso antes de la creación de la oms en 1946, la columna vertebral de la gobernanza de la salud en el hemisferio occidental es la ops. ${ }^{20}$ A través de sus vínculos orgánicos con la oms, la ops ha sido un importante interlocutor para la participación de los países de las Américas en el régimen mundial de seguridad. A lo largo de los años, la ops se dotó de una infraestructura impresionante y extensa, así como de recursos humanos especializados para combatir la propagación de enfermedades infecciosas en las Américas. Entre otras cosas, la Oficina Sanitaria Panamericana, secretariado de la ops, ha sido un pilar competente de la cooperación técnica para los sectores de salud entre sus 35 Estados miembros. La ops cuenta con un Centro de Operaciones de Emergencia y un Equipo de Trabajo para Alerta y Respuesta en casos de epidemias contra las amenazas de enfermedades transmisibles. La ops tiene también equipos de trabajo por país en todos sus miembros y ayudó a crear los centros nacionales de influenza en la mayoría de ellos, los cuales son cruciales para la vigilancia de las pandemias. Desde 2000, su Fondo Estratégico (Fondo Rotatorio Regional para Suministros Estratégicos de Salud Pública) ha dotado a los Estados miembros de un mecanismo para la adquisición y gestión de la cadena de sumi-

20 Sobre la historia de la ops, véase Marcos Cueto, El valor de la salud: Historia de la Organización Panamericana de la Salud, Washington, D.C., Organización Panamericana de la Salud, 2004. 
nistro de medicamentos esenciales, vacunas e insumos estratégicos de salud.

La organización ha sido fundamental para la transferencia de la gobernanza al prestar asistencia técnica a las autoridades de salud pública y a las y los expertos médicos de los Estados miembros. Por un lado, la ops ha trabajado para fortalecer las capacidades básicas del Estado en el marco del Rsi: detectar, evaluar, informar y responder de manera rápida y efectiva a emergencias potenciales o reales de salud pública. Por otra parte, ha reforzado las labores y capacidades gubernamentales para enfrentar una serie de enfermedades infecciosas que han plagado el hemisferio en las últimas dos décadas, incluyendo A/H1N1, dengue, fiebre amarilla, chikungunya y zika.

Si bien la ops se esforzó por anidar la arquitectura institucional panamericana en el régimen de seguridad sanitaria mundial basado en la oms, ${ }^{21}$ recientemente también se han observado tendencias de regionalización que han dado lugar a la construcción de mecanismos de gobernanza contra las enfermedades infecciosas, vinculados con las organizaciones y procesos de integración regional. Como ilustra el cuadro 1, los diferentes esquemas de integración regional desarrollaron su propia arquitectura de seguridad sanitaria con mandatos que se superponían con los de la ops y que aumentaban el número de stakeholders (partes) comprometidos con la gobernanza de salud hemisférica y regional. ${ }^{22}$

${ }^{21}$ En cuanto al desarrollo del régimen, véase Vinod K. Aggarwal (ed.), Institutional Designs for a Complex World: Bargaining, Linkages, and Nesting, Ithaca, Cornell University Press, 1998; Blavoukos Spyros y Dimitris Bourantonis, "Nested Institutions", en Rafael Biermann y Joachim A. Koops (eds.), Palgrave Handbook of Inter-Organizational Relations in World Politics, Londres, Palgrave Macmillan, 2017, pp. 303-315.

22 Véase también Paulo Bus y Sebastián Tobar, "Health Diplomacy in the Political Process of Integration in Latin America and the Caribbean", Oxford Research Encyclopedia of Global Public Health, 2018, pp. 1-24. 


\section{Cuadro 1 \\ Arquitectura de la seguridad sanitaria hemisférica pre-Covid-19}

\begin{tabular}{|c|c|c|}
\hline $\begin{array}{l}\text { Región/ } \\
\text { subregión }\end{array}$ & $\begin{array}{l}\text { Organización } \\
\text { regional }\end{array}$ & $\begin{array}{l}\text { Arquitectura de gobernanza de } \\
\text { seguridad sanitaria }\end{array}$ \\
\hline $\begin{array}{l}\text { Hemisferio } \\
\text { occidental }\end{array}$ & $\begin{array}{l}\text { Organización Mundial } \\
\text { de la Salud (oms) - } \\
\text { Organización } \\
\text { Panamericana de la } \\
\text { Salud (ops) }\end{array}$ & $\begin{array}{l}\text { Reglamento Sanitario Internacional (RSI), } \\
\text { establecido en 2005; Sistema Mundial de Vigilancia } \\
\text { y Respuesta a la Gripe de la oms (SMVRG), creado en } \\
\text { 1952; Oficina Sanitaria Panamericana (osP), creada } \\
\text { en 1902; Fondo Rotatorio Regional para Suministros } \\
\text { Estratégicos de Salud Pública (Fondo Estratégico), } \\
\text { establecido en 2000; Red Mundial de Vigilancia } \\
\text { de la Gripe de la oms (GISN, creado en 1952); } \\
\text { Red Mundial de Alerta y Respuesta ante Brotes } \\
\text { Epidémicos (GOARN, establecida en 2000); Centros } \\
\text { colaboradores OPS/oms. }\end{array}$ \\
\hline Iberoamérica & $\begin{array}{l}\text { Secretaría General } \\
\text { Iberoamericana (Segib) }\end{array}$ & $\begin{array}{l}\text { Programa Iberoamericano de Fortalecimiento } \\
\text { de la Cooperación Sur-Sur (PIFCss), creado en } \\
\text { 2007; Reunión Iberoamericana de Autoridades } \\
\text { Reguladoras de Medicamentos (Red EAMI), } \\
\text { establecida en 1997. }\end{array}$ \\
\hline $\begin{array}{l}\text { América } \\
\text { del Norte }\end{array}$ & & $\begin{array}{l}\text { Plan de América del Norte para los animales y la } \\
\text { influenza pandémica (NAPAPI), creado en 2007, } \\
\text { revisado en 2012; Órgano Superior de Coordinación } \\
\text { de América del Norte (SCB), establecido en 2010; } \\
\text { Grupo de Trabajo sobre la Seguridad Sanitaria } \\
\text { (HSWG), creado en 2010. }\end{array}$ \\
\hline $\begin{array}{l}\text { América Latina } \\
\text { y el Caribe }\end{array}$ & $\begin{array}{l}\text { Comunidad de Estados } \\
\text { Latinoamericanos y } \\
\text { Caribeños (Celac) }\end{array}$ & $\begin{array}{l}\text { Plan de Trabajo para 2020, propuesto por México, } \\
\text { creado en } 2019 .\end{array}$ \\
\hline Mesoamérica & $\begin{array}{l}\text { Proyecto de Integración } \\
\text { y Desarrollo de } \\
\text { Mesoamérica (PM) }\end{array}$ & $\begin{array}{l}\text { Sistema Mesoamericano de Salud Pública (smsP), } \\
\text { creado en 2011; Instituto Mesoamericano de Salud } \\
\text { Pública, creado en } 2009 .\end{array}$ \\
\hline Centroamérica & $\begin{array}{l}\text { Sistema de Integración } \\
\text { Centroamericana (Sica) }\end{array}$ & $\begin{array}{l}\text { Consejo de Ministros de Salud de Centroamérica } \\
\text { (Comisca), creado en 2003; Secretaría Ejecutiva del } \\
\text { Consejo de Ministros de Salud de Centroamérica } \\
\text { (sE-Comisca), creado en } 2007 .\end{array}$ \\
\hline Caribe & $\begin{array}{l}\text { Comunidad del Caribe } \\
\text { (Caricom) }\end{array}$ & $\begin{array}{l}\text { Agencia de Salud Pública del Caribe (Carpha), } \\
\text { establecida en 2011; Mecanismo de Coordinación } \\
\text { Regional para la Seguridad Sanitaria, creado en } 2017 .\end{array}$ \\
\hline
\end{tabular}




\begin{tabular}{|c|l|l|}
\hline Región andina & $\begin{array}{l}\text { Comunidad Andina de } \\
\text { Naciones (CAN) }\end{array}$ & $\begin{array}{l}\text { Organización Andina de Salud Hipólito Unanue } \\
\text { (Oras Conhu), creada en 1971. }\end{array}$ \\
\hline $\begin{array}{c}\text { Región } \\
\text { amazónica }\end{array}$ & $\begin{array}{l}\text { La Organización del } \\
\text { Tratado de Cooperación } \\
\text { Amazónica (OTCA) }\end{array}$ & $\begin{array}{l}\text { Comisión Especial de Salud de la Amazonía (Cesam), } \\
\text { creada en 1988. }\end{array}$ \\
\hline América del Sur & $\begin{array}{l}\text { Unión de Naciones } \\
\text { Suramericanas } \\
\text { (Unasur) }\end{array}$ & $\begin{array}{l}\text { Consejo Suramericano de Salud (CSs), 2008-2018; } \\
\text { Instituto Suramericano de Gobierno en Salud } \\
\text { (Isags), 2011-2019. }\end{array}$ \\
\hline Cono Sur & $\begin{array}{l}\text { Mercado Común del } \\
\text { Sur (Mercosur) }\end{array}$ & $\begin{array}{l}\text { Reunión de Ministros de Salud de Mercosur (RMS), } \\
\text { creado en 1995; Subgrupo de Trabajo sobre Salud } \\
\text { (sGT-11), creado en 1996. }\end{array}$ \\
\hline
\end{tabular}

Fuente: elaboración propia.

Algunos de los nuevos actores, como la Agencia de Salud Pública del Caribe (Carpha) de la Caricom y el Consejo Centroamericano de Ministros de Salud (Comisca) del Sica, gozaban de autoridad delegada, una secretaría permanente y sus propios recursos presupuestarios similares a los de la ops. Sin embargo, otras instituciones regionales de salud pública, como el Sistema Mesoamericano de Salud Pública (SMSP), el Plan de América del Norte para los Animales y la Influenza Pandémica (NAPAPI) y el Consejo Suramericano de Salud (CSs) fueron materializaciones de la segunda macrotendencia de gobernanza en las Américas: el interpresidencialismo. El interpresidencialismo puede definirse como un modo de gobernanza regional en el que las y los jefes de gobierno y de Estado proyectan su autoridad nacional en foros regionales y participan directa y colectivamente en la formulación de políticas y la toma decisiones regionales. Según la terminología de la teoría principal-agente (principalagent theory), como gobernantes, en la medida de lo posible, las y los presidentes prefieren gobernar directamente y como grupo, en vez de delegar autoridad a funcionarios gubernamentales o secretarías internacionales. ${ }^{23}$ En otras palabras,

${ }^{23}$ Sobre la teoría del agente principal en las relaciones internacionales, véase Darren G. Hawkins, David L. Lake, Daniel L. Nielsen y Michael 
optan por mantener con una rienda muy corta a los agentes nacionales o regionales que trabajan o ejecutan órdenes en su nombre. Las y los líderes latinoamericanos han gozado durante mucho tiempo de un cuasimonopolio del poder de decisión en política exterior nacional, gracias a la tradición histórica de los regímenes presidencialistas concentrados. Los recientes avances tecnológicos en las comunicaciones y el transporte, así como la tendencia diplomática mundial hacia la diplomacia de las cumbres presidenciales, han aumentado la proyección de su autoridad personal y activismo a nivel hemisférico y regional. ${ }^{24}$

El SMSP, la NAPAPI y la SAHC, que fueron fundidos en el molde interpresidencial, son ejemplos de instituciones regionales representativas de la creciente informalización de las instituciones mundiales y regionales de gobernanza en diversas áreas temáticas. ${ }^{25}$ Son instituciones de bajo costo cuyos

J. Tierney (eds.), Delegation and Agency in International Organizations, Cambridge, University Press, 2006.

24 Sobre el interpresidencialismo, véase Andrés Malamud, "Presidential Diplomacy and the Institutional Underpinnings of Mercosur: An Empirical Examination”, Latin American Review, vol. 40, núm. 1, 2005, pp. 138-164; Andrés Malamud, "Presidentialist Decision Making in Latin American Foreign Policy: Examples from Regional Integration Processes", en Jorge I. Domínguez y Ana Covarrubias (eds.), Routledge Handbook of Latin America in the World, Londres, Routledge, 2014, pp. 124-136. Sobre el auge de las cumbres presidenciales en las Américas, véase Carlos M. Jarque, María Salvadora Ortiz y Carlos Quenan (eds.), América Latina y la diplomacia de Cumbres, Ciudad de México, Secretaría General Iberoamericana, 2010; Gordon Mace, Jean Philippe Thérien, Diana Tussie y Olivier Dabène (eds.), Summits and Regional Governance: The Americas in Comparative Perspective, Nueva York, Routledge, 2016; Francisco Rojas (ed.), Globalización, América Latina y la diplomacia de las Cumbres, Santiago, Flacso-Chile, 1998; Laurence Whitehead y Alexandre Barahona, "Las cumbres mundiales y sus versiones latinoamericanas: ¿haciendo una montaña de un grano de arena?", América Latina Hoy, vol. 40, 2005, pp.15-27.

25 Véase Kenneth Abbott y Benjamin Faude, "Choosing Low-cost Institutions in Global Governance”, International Theory, versión en línea, 2020, pp. 1-30; Charles B. Roger, The Origins of Informality: Why the Legal Foundations of Global Governance are Shifting, and Why It Matters, Nueva York, Ox- 
miembros se benefician de su flexibilidad institucional, evitando intencionalmente la creación de burocracias internacionales, minimizando la inversión pública y manteniendo un estricto control soberano sobre la formulación y la implementación de políticas regionales de salud. ${ }^{26}$

Antes de la pandemia de Covid-19, la seguridad sanitaria en las Américas había evolucionado de un régimen mundial, con la oms y la ops como instituciones reforzadas o centrales, y con el Rsi como su estructura normativa, hacia un complejo de regímenes en expansión con una jerarquía institucional menos clara. ${ }^{27}$ Como en el caso reciente de la seguri$\mathrm{dad} /$ defensa y la protección de la democracia, este complejo de regímenes de seguridad sanitaria evolucionó hacia la yuxtaposición de las instituciones de gobernanza hemisféricas y regionales, de tal manera que la acción colectiva contra cualquier eventual pandemia comportaría un nexo de gobernanza hemisférica-regional. ${ }^{28}$ Es decir, las respuestas de la gobernanza, más allá de las acciones individuales de los Estados, necesariamente entrañarían alguna forma de interacción

ford University Press, 2020; Felicity Vabulas y Duncan Snidal, “Organization Without Delegation: Informal Intergovernmental Organizations (IIGOs) and the Spectrum of Intergovernmental Arrangements", Review of International Organizations, núm. 8, 2013, pp. 193-220.

${ }^{26}$ Kenneth Abbott y Benjamin Faude, art. cit.

${ }^{27}$ Según Alter y Raustiala, un complejo de regímenes puede definirse como "un conjunto de regímenes superpuestos y quizás incluso contradictorios que comparten un enfoque común”. Véase Karen J. Alter y Kal Raustiala, "The Rise of International Regime Complexity", Annual Review of Law and Social Science, vol. 14, 2018, p. 330. En cuanto a las instituciones reforzadas versus las amenazadas en regímenes complejos, véase Alexander Betts, "Regime Complexity and International Organizations: UNHCR as a Challenged Institution”, Global Governance, vol. 19, núm. 1, 2013, pp. 69-81. Para el concepto de instituciones $h u b$, véase Andrew Cooper y Richard Stubbs, "Contending Regionalisms: Hub and Challengers in the Americas and the Asia-Pacific”, The Pacific Review, vol. 30, núm. 5, 2017, pp. 615-632.

28 Véase Thomas Legler y Ornela Garelli-Ríos, "La protección de la democracia ante la crisis venezolana: los límites del nexo hemisférico-regional de gobernanza en las Américas”, Pensamiento Propio, núm. 47, 2018, pp. 159-188. 
en una arquitectura fragmentada entre organizaciones hemisféricas, como la ops, y los descendientes institucionales de los procesos de integración regional e interpresidencialismo enumerados en el cuadro 1, ya sea cooperativa, competitiva o conflictiva.

$\mathrm{El}$ riesgo potencial que presentaba este nexo era que las tensiones ideológicas o la divergencia de intereses entre los gobiernos a lo largo del hemisferio podrían conducir a un escenario de multilateralismo impugnado en caso de brote viral, en el que las instituciones hemisféricas y regionales, y sus respectivos actores, entrarían en conflicto o en una competencia debilitante en lugar de unir fuerzas. ${ }^{29}$ Esto es, en efecto, lo que sucedió en otra área temática que involucró un nexo de gobernanza hemisférico-regional: la defensa colectiva de la democracia respecto a la crisis multidimensional de Venezuela desde 2013. En ese caso, la Organización de Estados Americanos (OEA) y Unasur, con mandatos superpuestos, entraron en una dinámica competitiva y conflictiva que, en última instancia, debilitó las respuestas interamericanas y sudamericanas y facilitó la consolidación de un régimen autoritario bajo Nicolás Maduro. ${ }^{30}$

Cabe mencionar que Unasur sí pareció, al menos retóricamente, reivindicar una agenda sudamericana progresista de soberanía sanitaria, equidad y derechos, que podría haber colocado su nueva arquitectura, la SAHC y el Instituto Sudamericano de Gobierno en Salud (Isags), en conflicto con la ops. ${ }^{31}$

29 Sobre el multilateralismo impugnado, véase Julia Morse y Robert Keohane, "Contested Multilateralism", Review of International Organizations, núm. 9, 2014, pp. 385-412.

${ }^{30}$ Véase Thomas Legler y Ornela Garelli-Ríos, art. cit.; Thomas Legler y Detlef Nolte, "Venezuela: la protección regional multilateral de la democracia", Foreign Affairs Latinoamérica, vol. 19, núm. 2, 2019, pp. 43-41; Detlef Nolte, "Costs and Benefits of Overlapping Regional Organizations in Latin America: The Case of the OAS and UNASUR", Latin American Politics and Society, vol. 60, núm. 1, 2018, pp. 128-153.

31 Véase María Belén Herrero y Diana Tussie, "UNASUR Health: A Quiet Revolution in Health Diplomacy in South America", Global Social Policy, vol. 15, núm. 3, 2015, pp. 261-277; Pia Riggirozzi, "Regionalism, 
Según sus defensores más radicales, la agenda de la Unasur tenía como objetivo afirmar la soberanía sanitaria sudamericana frente a la visión proestadounidense y neoliberal de la gobernanza sanitaria panamericana, supuestamente defendida por la ops. ${ }^{32}$

Afortunadamente, ese choque de organizaciones y proyectos institucionales nunca ocurrió en el área de seguridad sanitaria. De hecho, desde 2004, la ops ha operado programas subregionales de cooperación técnica para el Caribe, Centroamérica y Sudamérica, en los que ha forjado lazos de colaboración y memorandos de entendimiento con organizaciones regionales y mecanismos de integración, incluyendo supuestos defensores del regionalismo poshegemónico en ese momento, como el Mercosur y la Unasur. ${ }^{33}$

Sin duda, la densa comunidad epistémica de expertos en salud pública, científicos y médicos que la ops había ayudado a cultivar en todo el hemisferio durante muchas décadas contrarrestó las voces políticas que abogaban por la creación de una esfera pública sudamericana distinta y autónoma. A pesar de las diferencias ideológicas entre sus jefes de Estado, los ministros de salud a lo largo de las Américas adoptaron por unanimidad iniciativas de planificación recientes de la ops, como la Agenda de Salud Sostenible para las Américas (2018-2030).

Activism, and Rights: New Opportunities for Health Diplomacy in South America”, Review of International Studies, vol. 41, núm. 2, 2015, pp. 407-428.

32 Gonzalo Basile, La salud del proceso de integración regional: El caso Unasur salud ¿soberanía o dependencia sanitaria?, Santo Domingo, Flacso República Dominicana, 2019, pp. 3-30.

33 Sobre el regionalismo poshegemónico, véase José Briceño-Ruiz e Isidro Morales (eds.), Post-Hegemonic Regionalism in the Americas: Toward a Pacific-Atlantic Divide? Londres, Routledge, 2017; Thomas Legler, "Posthegemonic Regionalism and Sovereignty in Latin America: Optimists, Skeptics, and an Emerging Research Agenda”, Contexto Internacional, vol. 35, núm. 2, 2013, pp. 325-352; Pía Riggirozzi y Diana Tussie (eds.), The Rise of Post-hegemonic Regionalism: The Case of Latin America, Cham, Springer, 2012. 
De hecho, afortunadamente hay más evidencia en el nuevo milenio sobre cooperación interinstitucional que sobre el conflicto entre la ops y sus contrapartes regionales. Esta colaboración condujo a un valioso acervo de experiencia y confianza obtenido en la lucha contra otras enfermedades infecciosas. Un caso importante a este respecto fue la estrecha coordinación que se produjo entre los ministros de salud de América del Sur, el css y la ops en la lucha contra el virus A/H1N1 en 2009. ${ }^{34}$

También hubo incidentes que demostraron el potencial de la ops para desempeñar el papel de orquestador en emergencias concretas de salud pública. Por ejemplo, la ops coordinó esfuerzos regionales para contrarrestar un brote de fiebre amarilla urbana en Paraguay en 2008. Además de desempeñar una función de asesoramiento en ese país, utilizó su Fondo Estratégico de manera eficaz y expedita para redirigir el suministro de vacunas de los países vecinos a fin de compensar la propia escasez de Paraguay en ese momento. ${ }^{35}$

En vísperas del brote de la Covid-19, una tendencia preocupante fue la desaceleración de los regionalismos y el multilateralismo regional que experimentaban varias partes de las Américas. ${ }^{36}$ A raíz de la crisis venezolana, la oEA sufrió

${ }^{34}$ Organización Mundial de la Salud, oms/Organización Panamericana de la Salud/ops, "Reunión de Ministros de Salud de la Unasur", 8 de agosto de 2009. Es importante señalar que el Mercosur ha sufrido su propia metamorfosis a lo largo de los años, según las inclinaciones ideológicas y el estado de las relaciones entre sus presidentes: desde ser una plataforma institucional para el regionalismo abierto durante el decenio de 1990, pasando por ser un defensor del regionalismo poshegemónico en el nuevo milenio, hasta su actual estancamiento institucional en el contexto de las tensiones interpresidenciales antes mencionadas.

35 Véase Jon Kim Andrus, Ximena Aguilera, Otavio Oliva, y Sylvain Aldighieri, "Global Health Security and the International Health Regulations", BMC Public Health, vol. 10, supl. 1, 2010, pp. 1 a 4.

${ }^{36}$ Véase José Briceño-Ruiz y Andrea Ribeiro Hoffmann, "The Crisis of Latin American Regionalism and Way Ahead", en Bettina de Souza Guilherme, Christian Ghymers, Stephany Griffith-Jones y Andrea Ribeiro Hoffmann (eds.), Financial Crisis Management and Democracy: Lessons from 
profundas divisiones ideológicas entre sus Estados miembros que obstaculizaron gravemente su capacidad de organizar la acción colectiva. Después de una estrecha coordinación entre los presidentes Felipe Calderón (2006-2012) y Barack Obama (2009-2017) y el primer ministro Stephen Harper (2006-2015) y sus gobiernos, a través del mecanismo de la NAPAPI durante el brote de A/H1N1 de 2009 y el posterior fortalecimiento de ese mecanismo en 2012, a partir de 2016, con la llegada de Donald Trump (2017-2021) a la presidencia de Estados Unidos, los líderes de América del Norte no lograron celebrar una sola cumbre. En 2018-2019, las tensiones ideológicas ${ }^{37}$ y las diferencias interpersonales entre los presidentes sudamericanos pusieron fin a la Unasur y a su institucionalidad de salud pública, el css y el Isags.

Estos acontecimientos pusieron de relieve el papel de los presidentes como eje de la cooperación regional (o su ausencia) y la vulnerabilidad potencial de la gobernanza sanitaria hemisférica y regional ante los altibajos en las relaciones entre los líderes del hemisferio y sus diferencias ideológicas. Como lo afirmó Stefano Palestini con respecto al posible inconveniente del interpresidencialismo, "la capacidad del re-

Europe and Latin America, Cham, Springer, 2021, pp. 281-293; Ana Covarrubias, “¿Unidad en la diversidad? La crisis del multilateralismo en América Latina”, El País, 12 de marzo de 2020; Detlef Nolte y Brigitte Weiffen (eds.), Regionalism Under Stress: Europe and Latin America in Comparative Perspective, Londres, Routledge, 2020; Nísia Trindade, Paulo Marchiori Buss y Rômulo Paes-Sousa, "COVID-19 Pandemic: A Health and Humanitarian crisis", Cuadernos de Saúde Pública, vol. 36, núm. 7, 2020, pp. 2-3; Cintia Quiliconi, "The Crossroads of Latin American Regionalism: A Cycle Shift or a Return to Open Regionalism?”, Linea Sur: Strategic Agenda and Integration, núm. 14, 2018, pp. 140-151; Alberto Van Klaveren, "La crisis del multilateralismo y América Latina”, Análisis 10/2020, Fundación Carolina, 10 de marzo de 2020.

37 Véase Donald Howard Avery, "The North American Plan for Avian and Pandemic Influenza: A Case Study of Regional Health Security in the 21st century", Global Health Governance, vol. 3, núm. 2, 2010, pp. 1-25; María Esther Coronado Martínez, "The Mexican Experience of the Napapi Revision Process”, Contexto Internacional, vol. 38, núm. 1, 2016, pp. 203-239. 
gionalismo impulsado por las cabezas del poder ejecutivo para ofrecer bienes regionales depende de las buenas relaciones y del liderazgo de los jefes de Estado (presidentes)". ${ }^{38}$ Como veremos en la siguiente sección, las acciones presidenciales o la ausencia de éstas pueden ser el talón de Aquiles de las respuestas hemisféricas y regionales al brote de la Covid-19. ${ }^{39}$

\section{TENDENCIAS DE GOBERNANZA CONTRA LA PANDEMIA EN LAS AMÉRICAS}

En contraste con las afirmaciones antes mencionadas de que las Américas han sufrido un colapso de la cooperación y coordinación regional ante la Covid-19, el ejercicio de mapeo capturado en el cuadro 2 indica la efervescencia de formas heterogéneas de cooperación y fortalecimiento institucional hemisférico y regional. En las páginas siguientes, mi lectura de las tendencias de la seguridad sanitaria y la gobernanza multisectorial en el contexto de la pandemia subraya que, mientras las formas interpresidenciales de gobernanza vinculadas estrechamente con las prerrogativas e interacciones presidenciales han experimentado un proceso de redefinición y han sufrido una serie de problemas, disfuncionalidades y reveses, lo que he denominado interpresidencialismo patológico, una plétora de organizaciones regionales y bancos de desarrollo han mostrado una sorprendente resiliencia y capacidad organizativa para la promoción de numerosas formas de orquestación y transferencia de la gobernanza.

${ }^{38}$ Stefano Palestini, art. cit., p. 15.

${ }^{39}$ Véase también David Baracaldo Orjuela y Jean-Marie Chenou, "Regionalism and Presidential Ideology in the Current Wave of Latin American Integration”, International Area Studies Review, vol. 22, núm. 1, 2019, pp. 41-63. 


\section{Cuadro 2}

\section{Respuestas de gobernanza a la Covid-19 en las Américas}

\begin{tabular}{|c|c|c|}
\hline \begin{tabular}{|c|} 
Área de asuntos \\
de gobernanza
\end{tabular} & $\begin{array}{l}\text { Organización Regional } \\
\text { formal / informal }\end{array}$ & $\begin{array}{l}\text { Formas de cooperación / } \\
\text { mecanismos institucionales }\end{array}$ \\
\hline \multirow[t]{6}{*}{$\begin{array}{l}\text { Seguridad } \\
\text { sanitaria }\end{array}$} & OPS & $\begin{array}{l}\text { oms, Plan Estratégico de Preparación y Respuesta } \\
\text { frente a la Covid-19; Plan Mundial de Respuesta } \\
\text { Humanitaria de las Naciones Unidas; Fondo } \\
\text { Estratégico para Medicamentos Esenciales y } \\
\text { Suministros de Salud Pública; equipos regionales } \\
\text { y nacionales del Sistema de Gestión de Incidentes } \\
\text { (IMST); } 27 \text { oficinas nacionales; Red Regional de } \\
\text { Vigilancia Genómica Covid-19. }\end{array}$ \\
\hline & Caricom & $\begin{array}{l}\text { Carpha; Mecanismo de Coordinación Regional para } \\
\text { la Seguridad Sanitaria; Grupo de Trabajo de Salud } \\
\text { sobre Coordinación Regional para la Gestión de la } \\
\text { Respuesta del Consejo para el Desarrollo Humano y } \\
\text { Social (Cohsod); Clúster de Seguridad de la Caricom. }\end{array}$ \\
\hline & Sica & $\begin{array}{l}\text { Comisca; Plan de Contingencia Regional; } \\
\text { Observatorio Regional Sica-Covid 19; Mecanismo } \\
\text { de Negociación Conjunta de Precios y Compra de } \\
\text { Medicamentos. }\end{array}$ \\
\hline & Mercosur & $\begin{array}{l}\text { Fondo de Convergencia Estructural del Mercosur } \\
\text { (Focem). }\end{array}$ \\
\hline & Celac & $\begin{array}{l}\text { Red de Expertos en Agentes Infecciosos y Enfer- } \\
\text { medades Emergentes y Reemergentes; asociación } \\
\text { público-privada con la Universidad de Oxford, As- } \\
\text { traZeneca y la Fundación Carlos Slim para la vacuna } \\
\text { Covid-19 AZD1222; Foro China-Celac. }\end{array}$ \\
\hline & Prosur & $\begin{array}{l}5 \text { cumbres presidenciales virtuales; } 5 \text { mesas de } \\
\text { trabajo temáticas y grupos de trabajo. }\end{array}$ \\
\hline \multirow[t]{3}{*}{$\begin{array}{c}\text { Respuestas } \\
\text { multisectoriales }\end{array}$} & Segib & $\begin{array}{l}\text { Red de Autoridades en Medicamentos de } \\
\text { Iberoamérica (EAMI); Plataforma de información: } \\
\text { Iberoamérica frente al Covid-19. }\end{array}$ \\
\hline & Cepal & $\begin{array}{l}\text { Observatorio Covid-19 en América Latina y el Ca- } \\
\text { ribe; Conferencia Regional sobre Desarrollo Social } \\
\text { en América Latina y el Caribe. }\end{array}$ \\
\hline & Alianza del Pacífico & Plan de Acción Covid-19. \\
\hline
\end{tabular}




\section{Cuadro 2 (conclusión)}

\section{Respuestas de gobernanza a la Covid-19 en las Américas}

\begin{tabular}{|c|c|c|}
\hline \multirow[t]{7}{*}{$\begin{array}{l}\text { Respuestas } \\
\text { multisectoriales }\end{array}$} & $\begin{array}{l}\text { OEA y el Sistema } \\
\text { Interamericano }\end{array}$ & $\begin{array}{l}\text { Red Interamericana de Compras Gubernamentales } \\
\text { (INGP); portal de consultas, foros y repositorio } \\
\text { sobre el mundo durante y después de la pandemia; } \\
\text { Grupo de Trabajo Conjunto de Cumbres } \\
\text { (GTCC); Guía de acción política para enfrentar la } \\
\text { pandemia del Covid-19; Red Interamericana de } \\
\text { Competitividad (RIAC), Aceleradora de Ideas; Red } \\
\text { Interamericana para la Administración Laboral, } \\
\text { Comisión Interamericwana de Educación; Comisión } \\
\text { Interamericana de Mujeres. }\end{array}$ \\
\hline & ОТСА & $\begin{array}{l}\text { OTCA y OPS - webinars sobre problemática de la } \\
\text { salud en la cuenca amazónica; Observatorio } \\
\text { Regional Amazónico; Red de Centros de } \\
\text { Investigación Amazónicos; Planes de Contingencia } \\
\text { para la Protección de la Salud en Pueblos Indígenas } \\
\text { Altamente Vulnerables y en Contacto Inicial. }\end{array}$ \\
\hline & IICA & $\begin{array}{l}\text { Portal: El IICA ante Covid-19; Estrategia del IICA } \\
\text { frente a la emergencia del Covid-19. }\end{array}$ \\
\hline & BID & $\begin{array}{l}\text { Plataforma sobre Coronavirus del Grupo BID; } \\
\text { financiamiento de vacunas Covid-19; socios del } \\
\text { sector privado; Mesa Redonda de Socios del Sector } \\
\text { Privado sobre el Futuro de América Latina y el } \\
\text { Caribe; } 7 \text { respuestas específicas y } 4 \text { áreas prioritarias. }\end{array}$ \\
\hline & CAF & $\begin{array}{l}\text { Línea de crédito de emergencia; línea de crédito } \\
\text { de emergencia para atención médica; Línea de } \\
\text { Crédito Contingente Regional de Apoyo Anticíclico } \\
\text { para la Emergencia generada por el Covid-19; } \\
\text { línea regional de crédito para eventos climáticos } \\
\text { extremos, terremotos, accidentes y epidemias en la } \\
\text { región; Programa de apoyo a los servicios públicos; } \\
\text { fondos de cooperación técnica no reembolsables; } \\
\text { Agenda Digital. }\end{array}$ \\
\hline & Fonplata & $\begin{array}{l}\text { Fondo especial de cooperaciones no reembolsables; } \\
\text { líneas especiales de financiación para la Covid-19. }\end{array}$ \\
\hline & BCIE & $\begin{array}{l}\text { Programa de Emergencia de Apoyo y Preparación } \\
\text { ante el Covid-19. }\end{array}$ \\
\hline
\end{tabular}

Fuente: elaboración propia. 


\section{Respuestas interpresidenciales a la pandemia}

El interpresidencialismo es el patrón de gobernanza que más ha alimentado las percepciones negativas sobre las respuestas hemisféricas y regionales a la pandemia descritas en la introducción. La pandemia ha sacado a la luz tanto lo mejor como lo peor en términos de protagonismo presidencial y cooperación interpresidencial frente a la Covid-19. Por el lado positivo, el presidente de Costa Rica, Carlos Alvarado Quesada (2018-), ha ganado elogios por su defensa internacional de una plataforma tecnológica, el Acceso Mancomunado a la Tecnología contra la Covid-19 (C-TAP), que facilitaría el acceso de los países a vacunas, medicamentos y otros productos sanitarios eficientes, así como por la creación de un Fondo para Aliviar la Economía COVID-19 (FACE, por sus siglas en inglés) de 500 millones de dólares, que proporcionaría asistencia financiera a las economías en desarrollo. ${ }^{40} \mathrm{El}$ presidente de México, Andrés Manuel López Obrador (2018- ), y su embajador ante las Naciones Unidas, Juan Ramón de la Fuente, encabezaron una coalición de más de 160 países que abogaron por el acceso equitativo del Sur a la medicina, las vacunas, y el equipo médico, en última instancia consagrado en la resolución 74/274 de la Asamblea General de las Naciones Unidas. ${ }^{41}$ Esto fue un antecedente de la campaña poste-

${ }^{40}$ Comisión Económica para América Latina, Cepal, "Costa Rica presenta propuesta de fondo para aliviar la economía Covid-19”, Santiago, 25 de septiembre de 2020.

${ }^{41}$ Pablo Arrocha y Juan Ramón de la Fuente, "Iniciativa de México para asegurar el acceso mundial a medicamentos, vacunas y equipos médicos, para enfrentar la Covid-19", 29 de abril de 2020, https:/ / www.justsecurity.org/69916/mexicos-initiative-to-ensure-global-access-to-medicines-va ccines-and-medical-equipment-to-face-covid19/; Secretaría de Relaciones Exteriores, SRE, "México Impulsa en Naciones Unidas propuesta para garantizar el acceso a medicamentos, vacunas y equipo médico para hacer frente al Covid-19", Ciudad de México, 17 de abril de 2020, https://www. gob.mx/sre/prensa/mexico-impulsa-en-naciones-unidas-propuesta-paragarantizar-el-acceso-a-medicamentos-vacunas-y-equipo-medico-para-hacerfrente-al-covid-19 (consulta del 22 de enero de 2021); Naciones Unidas, 
rior en la Asamblea Mundial de la Salud de la oms en mayo de 2020 para promover las futuras vacunas contra el virus como un bien público global.

Lamentablemente, en otras situaciones la actuación internacional de los presidentes ha sido menos admirable, ejemplificando un fenómeno de gobernanza que puede llamarse interpresidencialismo patológico: acciones políticas, inacción, comentarios, decisiones y políticas atribuibles a los presidentes, individual o colectivamente, que impiden o socavan la construcción o la continuación de formas eficaces de cooperación internacional. Una serie de interacciones interpresidenciales han puesto en peligro la salud pública internacional y los esfuerzos multisectoriales contra la pandemia.

Los presidentes Donald Trump y Jair Bolsonaro (2019- ) ejemplifican la manera en que actúa este fenómeno disfuncional. Durante el primer semestre de 2020, congelaron los pagos de las cuotas anuales por la membresía de sus países a la ops, equivalente a la suma de 110 millones de dólares y 24 millones de dólares, respectivamente. Recortaron este apoyo porque la organización había sido supuestamente cómplice del presunto trabajo forzoso y la trata de personas de aproximadamente 10000 médicos cubanos en zonas pobres de Brasil, Bolivia, Ecuador y El Salvador que participaron en un programa de asistencia médica patrocinado por Cuba. ${ }^{42}$ La precaria situación financiera de la ops se vio exacerbada por los pagos anuales pendientes de 1.646 mil millones de dólares que le debían no sólo Brasil y Estados Unidos, sino también Argentina, Chile, Colombia, México y otros. ${ }^{43}$

Asamblea General, AGNu, "Resolution adopted by the General Assembly on 20 April 2020, 74/24", Nueva York, 21 de abril de 2020.

42 David D. Kirkpatrick y José María León Cabrera, "How Trump and Bolsonaro Broke Latin America's COVID-19 Defenses”, The New York Times, 27 de octubre de 2020.

43 Arlene King, Jon Kim Andrus y J. Peter Figueroa, "Financial Crisis at PAHO in the Time of COVID-19: A Call for Action", The Lancet, vol. 396, núm. 10244, 2020, p. 96. 
Las tendencias patológicas también se evidenciaron en el cuestionamiento de la autoridad y las recomendaciones de salud pública de la oms y la ops por parte de los presidentes, precisamente en una coyuntura en que estos organismos necesitaban más apoyo y cumplimiento internacional. Por ejemplo, el 14 de abril de 2020, el presidente Trump suspendió las contribuciones de Estados Unidos a la oms, citando la supuesta manipulación de la organización por China y su falta de independencia respecto a aquel país en el contexto de la pandemia. ${ }^{44}$ Varios presidentes, entre ellos Trump, Bolsonaro, López Obrador y Daniel Ortega (2007- ), de Nicaragua, desoyeron o aceptaron tan sólo selectivamente las recomendaciones de salud pública de la oms o de la ops que eran políticamente convenientes, haciendo caso omiso de otras, o no cumplieron con las obligaciones de los países determinadas por el RSI con respecto a la Covid-19. Por ejemplo, el gobierno mexicano fue repetidamente criticado por la oms por su falta de pruebas de Covid-19, entre las tasas más bajas del mundo, y sus laxas medidas de mitigación. ${ }^{45}$

En medio de tensiones ideológicas y animosidades, los actuales líderes de Canadá, México y Estados Unidos no convocaron una cumbre extraordinaria de líderes norteamericanos ni invocaron a la Napapi contra el coronavirus. Las convocatorias semanales de coordinación trilateral entre los cancilleres de los países están muy lejos de alcanzar la estrecha colaboración multisectorial que se produjo entre los tres países frente al A/H1N1 en 2009. ${ }^{46}$ Las tensiones entre el

44 Véase Donald J. Trump, Carta dirigida al Director General de la Organización Mundial de la Salud, 18 de mayo de 2020.

45 "México subestima la magnitud de la epidemia de Covid-19: oms", Infobae, 21 de agosto de 2020; "La oms alerta de un problema serio en México por el aumento de casos y muertes de Covid-19", Noticias ONU, 30 de noviembre de 2020. Para más análisis sobre el caso mexicano, véase el artículo de María Esther Coronado Martínez en este dossier.

46 Secretaría de Relaciones Exteriores, SRE, "Fortalece SRE cooperación norteamericana frente a la pandemia de Covid-19", comunicado de prensa núm. 146, 12 de mayo de 2020. 
presidente Trump y el primer ministro Justin Trudeau (2015- ), de Canadá, contribuyeron a favorecer las medidas unilaterales o bilaterales de cada uno de los respectivos países de América del Norte.

Las tensiones interpresidenciales también han afectado la arquitectura institucional a lo largo de gran parte de América del Sur y su capacidad para servir de base al armado de respuestas organizadas contra la pandemia y sus efectos más extensos. De acuerdo con las quejas de varios estudiosos en este sentido, la desaparición de Unasur y su aparato institucional informal, el css y el Isags, en 2018-2019, eliminó un acervo crucial de años de experiencia colectiva basada en la colaboración interregional contra el A/H1N1, la chinkungunya, el dengue y el ébola, y dejó un vacío institucional en la salud pública regional en el peor momento posible. ${ }^{47}$ Respecto al nacionalismo de vacunas de los países del Norte, una amenaza para el acceso oportuno y equitativo de los países del Sur a las vacunas recientemente desarrolladas y aprobadas, ${ }^{48}$ la desaparición de Unasur significó que América del Sur también perdiera lo que alguna vez había sido una voz poderosa en favor de la justicia y la igualdad en materia de salud mundial y lo que habría sido un defensor influyente de estas vacunas como un bien verdaderamente público a nivel mundial.

La capacidad de Mercosur para movilizar una respuesta regional coordinada también se ha visto obstaculizada por una amarga disputa personal e ideológica entre el presidente brasileño Bolsonaro y el presidente argentino Alberto

${ }^{47}$ Véase Paulo M. Bus y Sebastián Tobar, "COVID-19 and Opportunities for International Cooperation in Health”, Cadernos de Sáude Pública Reports in Public Health, vol. 36, núm. 4, 2020, pp. 1-3; Pía Riggirozzi, "Coronavirus y el desafío para la gobernanza regional en América Latina”, art. cit.

${ }^{48}$ Sobre el problema del nacionalismo en materia de vacunas, véase por ejemplo: "Coronavirus: la advertencia de México ante la ONU por el ‘acaparamiento' de vacunas por parte de los países ricos”, BBC Mundo, 17 febrero de 2021. 
Fernández (2019- ). Las perspectivas de colaboración interpresidencial en el Mercosur se vieron aún más dañadas cuando el presidente de Paraguay, Mario Abdo Benítez (2018- ), señaló públicamente que Brasil era la principal amenaza para su país ante la propagación del coronavirus. ${ }^{49}$ Aunque los presidentes de la organización celebraron una reunión virtual el 18 de marzo de 2020, que desembocó en una declaración sobre la cooperación regional contra el virus, ${ }^{50}$ posteriormente no se organizaron reuniones adicionales de alto nivel. Estos dirigentes tampoco invocaron ni crearon ningún mecanismo regional para coordinar sus respuestas a la pandemia de manera más sistemática. Esta inacción se produjo a pesar de las opciones institucionales disponibles, como las reuniones de ministros de Salud o el Subgrupo de Trabajo sobre Salud (SGT-11), órganos que habían estado en funcionamiento desde mediados de los años noventa y que presumían una larga historia de colaboración transgubernamental. La aprobación de aproximadamente 12 millones de dólares del Fondo de Convergencia Estructural del Mercosur (Focem) para fortalecer la capacidad de una red de institutos de investigación entre los Estados miembros para detectar y tratar la Covid-19 fue uno de los pocos puntos que brillaron respecto a la cooperación conosureña durante la pandemia. ${ }^{51}$

Los impulsos antimultilaterales de Trump y Bolsonaro exacerbaron lo que era ya un grave déficit de liderazgo político en toda América, particularmente en América del Sur, en una coyuntura crucial en que la dirección interpresidencial para reforzar y apuntalar la cooperación regional era muy necesaria. Afectando a diversas áreas temáticas, esta

49 Alejandro Frenkel, "El Mercosur ante la Covid-19: de la disputa comercial a la amenaza sanitaria", Análisis 40/2020, Fundación Carolina, 24 de junio de 2020, p. 6 .

${ }^{50}$ Mercado Común del Sur, Mercosur, "Declaración de los presidentes del Mercosur sobre coordinación regional para la contención y mitigación del coronavirus y su impacto", Montevideo, 18 de marzo de 2020.

${ }^{51}$ Mercado Común del Sur, Mercosur, "Más fondos del Mercosur para combatir el Covid-19", Montevideo, 6 de octubre de 2020. 
brecha se heredó de antes del brote del coronavirus y puede rastrearse, en parte, en la falta de una nueva generación de líderes influyentes y carismáticos con agendas internacionalistas que reemplazaran a Lula (2003-2010), Hugo Chávez (19992013) y Obama, y que tuvieran su talento para construir un consenso pluralista. La ausencia de Brasil es particularmente trágica, dado el liderazgo histórico del país en la construcción de una gobernanza de salud mundial, hemisférica y sudamericana. ${ }^{52}$

Varios esfuerzos de otros líderes compensaron parcialmente la inacción de Trump y Bolsonaro. El gobierno mexicano utilizó su presidencia pro tempore de la Comunidad de Estados de Latinoamérica y el Caribe (Celac) para revitalizar ese organismo como posible mecanismo de coordinación para las respuestas colectivas contra la pandemia. Por primera vez, la Celac incursionó en la gobernanza sanitaria. Entre sus iniciativas, en 2020 lanzó una nueva red de virólogos, la Red de Expertos en Agentes Infecciosos y Enfermedades Emergentes y Reemergentes. Además, forjó una alianza estratégica para el intercambio de información interinstitucional y de mejores prácticas con la Cepal y la Organización de las Naciones Unidas para la Agricultura y la Alimentación (FAO). Sus esfuerzos de orquestación también incluyeron la tarea de desempeñar un papel como intermediario regional. En primer lugar, bajo los auspicios de la Celac, México y Argentina coordinaron una asociación público-privada con la Universidad de Oxford, AstraZeneca y la Fundación Carlos Slim para desarrollar y producir la vacuna AZD1222 y así garantizar su distribución entre los Estados miembros de la Celac. En segundo lugar, la Celac promovió el Foro China-Celac como conducto a través del cual se presentó como un interlocutor regional para el acceso a la cooperación técnica

${ }^{52}$ Véase el artículo de Deisy de Freitas Lima Ventura y Flávia Thedim Costa Bueno en este dossier. 
y al crédito de China. ${ }^{53}$ En una reunión ministerial virtual del Foro, celebrada el 22 de julio de 2020, China se comprometió a prestar 1000 millones de dólares a los países de ALC para financiar la adquisición de una eventual vacuna china. ${ }^{54}$ Por último, la Celac se ha convertido en un defensor líder en la lucha por el acceso equitativo del Sur a las vacunas y otros insumos médicos frente al nacionalismo de vacunas entre los países del Norte. ${ }^{55}$

En enero de 2020, el presidente Bolsonaro anunció la retirada de Brasil de la Celac con el argumento de que dicho grupo toleraba la membresía de gobiernos autoritarios como Cuba, Nicaragua y Venezuela. ${ }^{56}$ En consecuencia, la redefinición de la gobernanza interpresidencial en el contexto de la Covid-19 se ha desarrollado en parte de acuerdo con una división ideológica entre gobiernos de izquierda, como México y Argentina, que han movilizado a la Celac como eje de acción autónoma de América Latina y el Caribe (ALC), y el Foro para el Progreso y el Desarrollo de América del Sur (Prosur) como entidad interpresidencial para los gobiernos de centro derecha.

El gobierno de Sebastián Piñera (2018- ) de Chile también buscó mejorar el vacío de liderazgo interpresidencial a través de su presidencia pro tempore de Prosur y la Alianza del Pacífico. En marcado contraste con el inmovilismo del Mercosur, Prosur realizó cinco reuniones presidenciales virtuales y una serie de encuentros por videoconferencia entre sus ministros de salud y coordinadores nacionales para promover el diálogo y la cooperación entre los ocho Estados miem-

${ }^{53}$ Adrián Bonilla Soria y Lorena Herrera-Vinelli, "Celac como vehículo estratégico de relacionamiento de China hacia América Latina (20112018)", Revista CIDOB d'Afers Internacionals, núm. 124, 2020, pp. 173-198.

${ }^{54}$ Diego Oré, "Mexico says China plans $\$ 1$ billion loan to ease Latam access to virus vaccine”, Reuters, 22 de julio de 2020.

${ }^{55}$ Secretaría de Relaciones Exteriores, SRE, "La Celac promueve la solidaridad y acceso equitativo a vacunas e insumos para hacer frente al Covid-19", comunicado núm. 064, 4 de febrero de 2021.

56 "Brasil abandona la Celac", El Universal, 16 de enero de 2020. 
bros, así como Bolivia y Uruguay. Creó cinco mesas de trabajo temáticas y grupos de trabajo para fomentar la acción intergubernamental y transgubernamental frente a la Covid-19 sobre una serie de cuestiones, incluidas las medidas en las fronteras y la repatriación, los viajes de personas y bienes, las compras conjuntas de insumos médicos y el intercambio de conocimientos epidemiológicos. Parece que Prosur ha hecho algunas contribuciones modestas para solucionar el vacío institucional en salud pública regional dejado por el colapso de Unasur y el estancamiento del Mercosur. ${ }^{57}$

Por su parte, en abril de 2020, la Alianza del Pacífico (AP) adoptó un "Plan de Trabajo frente al Covid-19" de trece puntos. Bajo la presidencia pro tempore de Chile y elaborado por el Grupo de Alto Nivel de viceministros de Relaciones Exteriores y Comercio de la AP, el documento contiene una agenda conjunta para responder a los efectos económicos y sociales de la pandemia en Chile, Colombia, México y Perú. ${ }^{58}$ Hacia fines de 2020, Colombia sustituyó oficialmente a Chile en la PPT de Prosur y la AP.

Finalmente, el presidente de España, Pedro Sánchez (2018- ), intentó revivir el iberoamericanismo en el contexto de la brecha de liderazgo presidencial en ALC. El 24 de junio de 2020, el gobierno español fue anfitrión de una conferencia virtual de alto nivel titulada "Juntos por una respuesta para América Latina y el Caribe ante la Covid-19”, a la que asistieron once presidentes y primeros ministros. El gobierno de Sánchez trató de posicionarse como interlocutor de una coalición de países de ALC con respecto a las instituciones financieras internacionales en un esfuerzo por obtener una mayor asistencia financiera y técnica para ellos, a fin de abordar las consecuencias socioeconómicas de la pandemia. ${ }^{59}$

57 Foro para el Progreso y el Desarrollo de América del Sur, Prosur, "Informe de gestión Prosur", Santiago, marzo de 2019-diciembre de 2020.

58 Alianza del Pacífico, Ap, "Plan de Trabajo frente al Covid-19", Santiago, abril de 2020.

59 Gobierno de España, La Moncloa, "President of the Government Chairs the High-Level Conference entitled 'United in providing a respon- 
Orquestación y transferencia de la gobernanza por organizaciones regionales

En contraste con los problemas mencionados con el interpresidencialismo, las organizaciones hemisféricas y regionales formales del hemisferio occidental y los bancos de desarrollo han mostrado una capacidad organizativa y una resiliencia sorprendentes. Como lo destaca la lista de iniciativas y mecanismos institucionales enumerados en el cuadro 2, han montado una plétora de formas de orquestación y transferencia de la gobernanza en respuesta a las repercusiones sanitarias, económicas y sociales de la pandemia. La experiencia de la Covid-19 ha puesto de relieve que muchas de estas entidades cuentan con secretarías altamente capaces y, por lo tanto, no toda la actividad de cooperación depende directamente de la autoridad o iniciativa presidencial (o de la falta de ésta). En consecuencia, el interpresidencialismo patológico ha sido compensado en cierta medida por el liderazgo institucional aportado por estos actores organizacionales. ${ }^{60}$

Para reiterarlo, la orquestación como un modo de gobernanza implica acciones en que las organizaciones regionales (OR) o los bancos de desarrollo participan en la intermediación, el establecimiento de agendas y la asistencia frente a los actores intermediarios que pueden incluir a otras organizaciones, redes transnacionales, empresas privadas y autoridades públicas de los Estados miembros. ${ }^{61}$ Como orquestadores, las or y los bancos también llevan a cabo diversas formas de transferencia de la gobernanza con respecto a sus Estados

se for America and the Caribbean to COVID-19", Madrid, 24 de junio de 2020, https://www.lamoncloa.gob.es/lang/en/presidente/news/Pa ginas/2020/20200624la-conference.aspx (consulta del 23 de enero de 2021).

${ }^{60}$ En cuanto al liderazgo institucional internacional, véase John Ikenberry, "The Future of International Leadership", Political Science Quarterly, vol. 111, núm. 3, 1996, pp. 358-402.

61 Stefano Palestini, art. cit. 
miembros, como el fortalecimiento institucional, las formas materiales de asistencia y el desarrollo de capacidades. ${ }^{62}$

La ops ha sido ejemplar en este sentido. A pesar de su déficit de ingresos, antes mencionado, organizó una impresionante serie de actividades contra el brote en colaboración con otras organizaciones, autoridades de salud pública, asociados privados y sectores de la sociedad civil. ${ }^{63}$ Es importante señalar que las y los funcionarios públicos internacionales de la ops emprendieron estas operaciones a diario, en gran medida a distancia del control de presidentes y gobiernos, como verdaderos orquestadores de la gobernanza.

Las conmociones en el suministro mundial hicieron difícil que los gobiernos individuales, en particular los de Estados débiles, compraran suministros y equipos médicos en los mercados internacionales por sí solos y a precios favorables. Ante este desafío, la oms y la ops, y mecanismos como la Red Interamericana de Compras Gubernamentales, han tratado de mejorar el poder de mercado de los países de las Américas, mediante la facilitación y el financiamiento de la puesta en común de su demanda y sus compras. A este respecto, la ops actuó como intermediario en nombre de sus Estados miembros a través de su Fondo Rotatorio Regional para el Suministro de Productos Estratégicos de Salud Pública. La organización también aprovechó su Fondo Rotatorio para que sirviera de mecanismo de adquisición de vacunas antiCovid-19 a través del Mecanismo de Acceso Mundial a las Vacunas contra la COVID-19 (Covax) de la oms.

La ops también se estableció como un centro clave de información y comunicaciones, incluyendo la creación del GeoHub Covid-19: Sistema de Información para la Región de las Américas, con cuatro puntos nodales subregionales. ${ }^{64}$

62 Tanya Börzel y Vera Van Hüllen, art. cit.

${ }^{63}$ Las siguientes referencias a las iniciativas de la ops provienen en gran medida de la ops, "Response to COVID-19 Outbreak in the Region of the Americas", versión 3, Washington, D.C., 28 de agosto de 2020.

${ }^{64}$ Organización Panamericana de la Salud, ops, "Geohub COVID-19 - Information System for the Region of the Americas (Sistema de Infor- 
En los frentes de inteligencia e investigación en salud, coordinó la Red Regional de Vigilancia Genómica Covid-19, a través del cual trece países compartieron sus secuencias genómicas de manera oportuna con la Iniciativa GISAID. ${ }^{65}$ Con el fin de mejorar la preparación de los países para recibir, almacenar, distribuir y administrar las nuevas vacunas antiCovid-19, la ops, en colaboración con la oms, el Fondo Internacional de las Naciones Unidas para la Infancia (UNICEF) y el Banco Mundial también creó y coordinó la herramienta de preparación para la introducción de vacunas (Virat), en la que 30 países de ALC compartieron información sobre su organización para la vacunación. ${ }^{66}$

Una de las razones por las que la ops ha mantenido su relevancia es su capacidad de recaudación de fondos, algo que le ha permitido superar sus desafíos financieros. En 2020, la ops reunió 263 millones de dólares para sus actividades previstas. ${ }^{67}$ De acuerdo con un comunicado de prensa oficial:

Con estos aportes, la cooperación técnica a países y la compra de suministros y equipos esenciales por parte de la ops pudieron lograr 119 envíos de equipo de protección personal a 34 países, 21.4 millones de pruebas PCR de Covid-19 a 36 países y territorios, además de 224 sesiones de capacitación sobre realización de pruebas, seguimiento y atención a pacientes. Como componente central de la orientación técnica

mación para la Región de las Américas del Geo-Hub COVID-19)", https:/ / paho-covid19-response-who.hub.arcgis.com/ (consulta del 23 de enero de 2020).

65 Sobre la Iniciativa Gisaid, véase Gisaid, https://www.gisaid.org/ (consulta del 23 de enero de 2020).

${ }^{66}$ Organización Panamericana de la Salud, ops, "La ops insta a países de las Américas a robustecer su preparación para la vacunación contra la Covid-19", Washington, D.c., 9 de febrero de 2021.

${ }^{67}$ Organización Panamericana de la Salud, ops, "La ops recauda \$263 MDD en 2020 para combatir la Covid-19 en la Región de las Américas", Washington, D.C., 12 de enero de 2021. 
de la ops a los países, también se difundieron 111 directrices y recomendaciones. ${ }^{68}$

Los presidentes del Sica y los primeros ministros de la Caricom se apresuraron a celebrar reuniones de emergencia al comienzo del brote y a autorizar a sus respectivas organizaciones regionales de salud pública a gestionar la crisis del coronavirus a nivel regional. Comisca y Carpha destacaron por la coordinación de sus esfuerzos de salud pública en sus respectivas subregiones. Por ejemplo, tras una cumbre virtual especial celebrada el 12 de marzo de 2020, los líderes centroamericanos aprobaron rápidamente un plan de contingencia centroamericano contra la Covid-19, que fue aprobado el 26 de marzo y contempló un papel fundamental para el Comisca en la coordinación de los esfuerzos regionales de seguridad sanitaria y para que el Banco Centroamericano de Integración Económica (BCIE) proporcionara un financiamiento de 1.9 mil millones de dólares para las necesidades multisectoriales de los miembros del Sica. ${ }^{69}$

Carpha construyó una de las respuestas más eficaces del mundo a la Covid-19 al demostrar el potencial de sinergia entre la iniciativa presidencial y la orquestación. ${ }^{70}$ Los ministros de salud y los jefes de gobierno del Caribe respondieron rápidamente, consultando a expertos en enfermedades infecciosas en enero, activando el Mecanismo Coordinador Regional para la Seguridad Sanitaria el 29 de enero, y celebrando reuniones de emergencia para ministros el 3 de febrero, y para líderes nacionales el 1 de marzo de 2020. Carpha ayudó a los funcionarios gubernamentales y a las autoridades sanita-

68 Ibid.

${ }^{69}$ Sistema de la Integración Centroamericana, Sica, "Plan de contingencia Regional: Orientando a complementar los esfuerzos nacionales para la prevención, contenido y tratamiento del Covid-19”, San Salvador, 2020.

${ }^{70}$ Comunidad del Caribe, Caricom, "News Feature: Caribbean Community successfully keeps low COVID-19 infection rates", Georgetown, 13 de julio de 2020. 
rias a elaborar a toda velocidad un protocolo regional y su respuesta multiinstitucional y multisectorial a la pandemia se organizó a través del mecanismo de coordinación antes mencionado. ${ }^{71}$

Vale la pena considerar brevemente por qué el Sica y la Caricom fueron más decisivos y eficaces en la movilización de su arquitectura de seguridad sanitaria para una acción concertada contra el coronavirus que los mecanismos interpresidenciales informales anteriormente mencionados. Cabe señalar que los regionalismos de América Central y el Caribe no habían sufrido el mismo grado de crisis que sus contrapartes de América del Norte o del Sur antes de la pandemia. Kevin Parthenay señala que estas subregiones han gozado de resiliencia regional, a pesar de las crisis recurrentes entre los Estados miembros individuales. Según Parthenay, a largo plazo, Centroamérica y el Caribe se han beneficiado de legados regionales duraderos como espacios imaginados, históricamente construidos, que perduran como mapas mentales en las mentes de sus habitantes. También ayuda que organismos como Comisca y Carpha hayan gozado de una considerable autonomía burocrática frente a sus patrones gubernamentales, en gran medida gracias al apoyo técnico y financiero continuo de actores externos como las agencias donantes occidentales, asiáticos y la Unión Europea. ${ }^{72}$

La eficacia del aparato regional de gobernanza de la salud de la Caricom también puede atribuirse, en parte, a la experiencia acumulada obtenida frente a amenazas anterio-

${ }^{71}$ Stephanie Fletcher-Lartey, Lisa Indar, Tamu Davidson, Gabriel González Escobar y Joy St John, "Protecting Health Security in the Caribbean: A Coordinated Regional Response to the Novel Coronavirus Disease (COVID-19) and Other Global Public Health Threats", International Public Health Journal, vol. 12, núm. 1, 2020, pp.33-45.

72 Véase el artículo de Kevin Parthenay en este dossier especial, así como Kevin Parthenay, "Why Central American Regionalism Never Ends Dying: A Historical Exploration of Regional Resilience”, en José BriceñoRuiz y Andrés Rivarola Puntigliano (eds.), Regionalism in Latin America: Agents, Systems, and Resilience, Nueva York, Routledge, 2020, pp. 31-49. 
res de enfermedades transmisibles. Asimismo, es una obviedad que los pequeños Estados individuales que forman la Comunidad deben unir sus fuerzas para garantizar su seguridad sanitaria, dada su capacidad y recursos estatales son extremadamente limitados.

Gracias a la rápida transformación de la problemática de la gobernanza pandémica, desde una crisis de salud pública hasta llegar a un desafío multidimensional, ha habido una expansión dramática de la arquitectura de la gobernanza y de las actividades de orquestación de las organizaciones hemisféricas y regionales. Esto, a su vez, llevó a una mayor diversificación del complejo de regímenes para la seguridad sanitaria que había surgido antes del brote de la Covid-19. La institucionalidad de la seguridad sanitaria existente, descrita en la sección anterior, resultó insuficiente para los desafíos no relacionados con la salud que presentaba la pandemia. El RSI de 2005 contempló el potencial de efectos indirectos de las emergencias de salud pública en el comercio y el transporte internacionales, pero nada en la escala de las reverberaciones multisectoriales que ha causado la Covid-19. Entre ellas figuraban la perturbación de las cadenas mundiales y regionales de suministro, tanto médicas como no médicas; las desaceleraciones económicas, el aumento del desempleo y la contracción del turismo, los cuellos de botella financieros, la difícil situación de la migración y las/los refugiados, las amenazas a la seguridad alimentaria y una serie de problemas humanitarios, así como de derechos humanos y democracia. Al afectar sus propios mandatos, estos problemas dramáticos incitaron a numerosas organizaciones hemisféricas y regionales, bancos de desarrollo y mecanismos a entrar en la contienda de maneras novedosas.

Además de la actividad organizativa individual, los esfuerzos de orquestación impulsaron una oleada de interacciones interorganizacionales en las que participaron on formales e informales. Un ejemplo de ello es el Grupo de Trabajo Conjunto de Cumbres (GTCC), creado originalmente para apoyar el proceso de Cumbres de las Américas, pero movilizado por 
su actual troika (Panamá, Perú y Estados Unidos) y la oEA en abril de 2020 como mecanismo de coordinación para sus 13 instituciones interamericanas e internacionales participantes y los países de las Américas. Durante 2020, el GTCC celebró cuatro reuniones virtuales de alto nivel para tratar diversos temas relacionados con la pandemia. La ops mantuvo estrechos vínculos de trabajo con las contrapartes regionales de las Américas a través de sus tres programas de cooperación subregional en el Caribe, Centroamérica y Sudamérica. También unió fuerzas con la Cepal para impulsar la promoción conjunta de recomendaciones de política y mejores prácticas en una serie de áreas temáticas afectadas por el brote.

Las oR centraron gran parte de su labor y energía en promover el intercambio de información, mejores prácticas y recomendaciones de políticas públicas. Por ejemplo, la ops desarrolló varias plataformas electrónicas: el Covid-19 Sistema de Información Covid-19 para la Región de las Américas, y la base de datos electrónica Orientación sobre la Covid-19 y últimas investigaciones en las Américas. La Secretaría General Iberoamericana (Segib) lanzó la plataforma electrónica Iberoamérica frente al Covid-19. Sica creó el Observatorio Regional SICA-Covid-19.73

Bajo petición de la Celac, la Cepal creó el Observatorio Covid-19 en ALc. Por su parte, la oea ha desarrollado la plataforma Post Covid-19: Portal oeA para Consultas, Foros y Repositorio, así como la Comunidad Virtual de los Sistemas de Emergencia y Seguridad de las Américas. El Sistema Económico Latinoamericano y del Caribe (sELA) ofrece su propio repositorio de acciones, medidas, políticas y mejores prácticas adoptadas por los gobiernos latinoamericanos y caribeños. ${ }^{74}$ En agosto de 2020, el Programa Iberoameri-

${ }^{73}$ Véase Sica, "Observatorio Regional Sica-Covid 19", https://www.si ca.int/coronavirus/observatorioSICACOVID19\# (consulta del 23 de enero de 2021).

${ }^{74}$ Sistema Económico Latinoamericano y del Caribe, SELA, "COVID-19: Resumen de las principales medidas, acciones y políticas", Caracas, 9 de diciembre de 2020, http://www.sela.org/media/3219723/ 
cano de Fortalecimiento de la Cooperación Sur-Sur (PIFCSs), afiliado a la Segib, invocó el Mecanismo Estructurado para el Intercambio de Experiencias de Cooperación Sur-Sur (MECSs) para lanzar una nueva iniciativa de financiación, "Socios frente al Covid-19", para fortalecer las capacidades Sur-Sur y triangular, con vistas al intercambio de información y experiencias relacionadas con el coronavirus. ${ }^{75}$

Los cínicos podrían descalificar gran parte de esta actividad organizativa centrada en el intercambio de conocimientos como diplomacia de bajo costo. Es decir, lo que se puede llevar a cabo con presupuestos limitados concentra una cantidad importante de iniciativas de gobernanza en actividades en línea: webinars, talleres, plataformas electrónicas, etcétera. En consecuencia, sirve más por su valor simbólico y gran visibilidad para señalar que las or estuvieron activas en la lucha contra la Covid-19, que para responder a las verdaderas necesidades materiales más urgentes de los gobiernos de la región. Sin embargo, este cinismo no tiene en cuenta que la pandemia dejó al descubierto una serie de brechas de gobernanza que sólo podían cubrirse mediante una acción colectiva urgente. ${ }^{76}$ Por ejemplo, el brote reveló el amplio vacío de información, conocimiento y comunicación sobre el hasta entonces desconocido virus. De manera similar, los daños socioeconómicos y desafíos de seguridad y políticos sin precedentes causados por la pandemia dieron lugar a la necesidad de llenar las brechas de políticas públicas, ya que los países carecían de experiencia previa en la formulación de políticas para hacer frente a problemas de esta índole.

covid-19-resumen-de-las-principales-medidas-estados-miembros-sela.pdf (consulta del 23 de enero de 2021).

75 Secretaría General Iberoamericana, Segib, “Socios frente al Covid-19', convocatoria para el fortalecimiento de la Cooperación Sur-Sur en Iberoamérica”, Madrid, 6 de agosto de 2020, https://www.segib.org/call/ socios-frente-al-covid-19-convocatoria-para-el-fortalecimiento-de-la-coope racion-sur-sur-en-iberoamerica/ (consulta del 23 de enero de 2021).

76 Para el análisis de las brechas de gobernanza, véase Thomas G. Weiss, Global Governance: What? Why? Whither?, Cambridge, Polity, 2013. 
Pero las on han hecho mucho más que facilitar el intercambio de información. Los bancos regionales de desarrollo del hemisferio han destinado contribuciones importantes al alivio de las dificultades financieras de sus Estados miembros. El Banco Interamericano de Desarrollo (BID) facilitó casi 800 millones de dólares en asistencia financiera a los Estados miembros para gastos relacionados con la salud, así como más de 2.15 mil millones de dólares para fines no relacionados con la salud. ${ }^{77}$ Además, el 23 de marzo de 2020, el Banco de Desarrollo de América Latina (CAF) lanzó una línea de crédito de emergencia de 2.5 mil millones de dólares para sus Estados miembros. ${ }^{78}$ La información disponible indica que el CAF autorizó cerca de 300 millones de dólares para necesidades relacionadas con la salud y casi $9.5 \mathrm{mil} \mathrm{mi-}$ llones de dólares para gastos no relacionados con la salud, de los cuales más de 5000 millones de dólares se destinaron a los problemas económicos causados por la pandemia. ${ }^{79} \mathrm{En}$ septiembre de 2020, el Fondo Financiero para el Desarrollo de la Cuenca del Plata (Fonplata) ofreció asistencia financiera a sus Estados miembros por un monto de 121 millones de dólares, de los cuales aproximadamente 36 millones se destinaron a gastos relacionados con la salud y casi 85 millones a

${ }^{77}$ Estas estadísticas fueron recopiladas por el autor sobre la base de los datos disponibles en el sitio web del Banco Interamericano de Desarrollo, BID, IDB Projects, https://www.iadb.org/en/projects-search?co untry $=\&$ sector $=\&$ status $=\&$ query $=$ COVID (consulta del 24 de enero de 2021).

${ }^{78}$ Banco de Desarrollo de América Latina, CAF, "COVID19: CAF makes USD 2.5 billion available for countries to protect their population and economies", Caracas, 23 de marzo de 2020, https://www.caf.com/en/currently/news / 2020/03/covid19-caf-makes-usd-25-billion-available-forcountries-to-protect-their-population-and-economies/ (consulta del $24 \mathrm{de}$ enero de 2021).

${ }^{79}$ Estas cifras son el resultado de cálculos derivados de las secciones "proyectos" y "Noticias" del sitio web del Banco de Desarrollo de América Latina, CAF, https:/ / www.caf.com/es/proyectos / ?kw=covid\&parent=0\&sd $=\& e d=\&$ reset $=$ false $($ consulta del 24 de enero de 2021). 
programación económica. ${ }^{80} \mathrm{El}$ Banco Centroamericano de Integración Económica (BCIE) y el Banco de Desarrollo del Caribe también fueron importantes prestamistas.

\section{CONCLUSIÓN: PRESIDENTES Y ORQUESTADORES CONTRA} EL CORONAVIRUS

El mapeo de las respuestas colectivas a la pandemia, el corazón de este artículo, invita a matizar las afirmaciones según las cuales las Américas han sufrido un colapso en la cooperación y un giro pendular hacia las respuestas nacionales a la Covid-19. Por el contrario, el hemisferio occidental ha experimentado una oleada de actividades de gobernanza heterogéneas contra la pandemia. A pesar de la fragmentación, el estancamiento institucional y las tensiones ideológicas que han plagado al continente en los últimos años, la efervescencia cooperativa que ha ocurrido responde a una necesidad urgente de pragmatismo y a un imperativo organizativo dictado por el hecho de que los Estados simplemente carecen de los recursos internos y las capacidades institucionales para hacerlo solos.

Es tentador descalificar este hervor de actividad organizativa sobre la base de las deprimentes estadísticas mundiales de la Covid-19 en el hemisferio occidental y América Latina y el Caribe, que están entre las peores del mundo. Sin embargo, contrafactualmente, no cabe duda de que el número de casos y muertes relacionados con el coronavirus, así como el sufrimiento humano por la pandemia, habrían sido aún peores si hubiera prevalecido una situación de "sálvese quien pueda”, y los presidentes hubieran llevado la batuta ellos so-

${ }^{80}$ Estos datos se basan en la información disponible en el sitio web de Fonplata: Fondo de Desarrollo Financiero de la Cuenca del Plata, Fonplata,, "Apoyo de Fonplata en respuesta al Covid-19 para los países miembros", https://www.fonplata.org/es/noticias/23-09-2020/apoyo-de-fonpla ta-en-respuesta-al-covid-19-para-los-paises-miembros (consulta del 24 de enero de 2021). 
los. Además, experiencias como la de la Caricom, donde la yuxtaposición de la acción coordinada de los primeros ministros, las respuestas de los países y la orquestación de la Carpha apuntalaron una historia de éxito relativo contra la pandemia, ciertamente ilustran el potencial de la cooperación regional. Como lo han señalado Ana B. Amaya y Philippe de Lombaerde, "Aunque la cooperación regional no es la bala de plata que resolverá los problemas causados por la Covid-19, puede ser parte de la solución, particularmente en el Sur Global". 81

He tratado de mostrar que las potencialidades, límites, y brechas de la acción colectiva que se han manifestado en patrones de cooperación concretos y desiguales durante la pandemia concuerdan con la vinculación de dos macrotendencias históricas de gobernanza establecidas en el hemisferio occidental antes del brote del coronavirus: la consolidación del régimen mundial de seguridad sanitaria tras la aprobación del Rsi en 2005 bajo la coordinación de la ops, y la expansión de la arquitectura de salud pública vinculada a los procesos de integración regional a través de un modo de gobernanza interpresidencial. Ya antes de que el flagelo de la Covid-19 azotara el hemisferio, los esfuerzos de orquestación de la ops, en sincronización con otros organismos y mecanismos regionales de seguridad sanitaria, mostraron una vitalidad y una promesa considerables contra las amenazas de enfermedades contagiosas en el hemisferio. A la vez, hubo indicios de que los aparatos de gobernanza construidos bajo los auspicios del Mercosur, el trilateralismo norteamericano y la Unasur eran vulnerables a las tensiones ideológicas y a las animosidades entre los jefes de Estado y de gobierno.

Cuando la crisis de la Covid-19 se desplegó en lugares como América del Norte, América del Sur y el Cono Sur, fue precisamente la arquitectura construida bajo el modo de go-

${ }^{81}$ Ana B. Amaya y Philippe de Lombaerde, "Regional Cooperation Is Essential to Combatting Health Emergencies in the Global South", Globalization and Health, vol. 17, núm. 9, 2021, p. 5. 
bierno interpresidencial la que demostró su debilidad para llevar a cabo la acción colectiva contra el virus. De hecho, he subrayado en estas páginas que ha habido numerosos casos de activismo o proyección de autoridad presidencial, perjudiciales para los asuntos hemisféricos o regionales, que impidieron la cooperación o pusieron a las poblaciones en riesgo innecesario, lo que conceptualicé como interpresidencialismo patológico.

Para ser justos, como lo señalé anteriormente, también se han producido algunos acontecimientos positivos importantes relacionados con las iniciativas interpresidenciales $a d$ hoc, de iniciativas individuales, así como de or informales como Celac y Prosur. En el momento de redactar este artículo, estas respuestas a la pandemia sugieren que podría estar en marcha una recomposición del terreno de la gobernanza hemisférica y regional del interpresidencialismo.

Por otro lado, la ops y una serie de otras organizaciones hemisféricas y regionales y bancos de desarrollo han mostrado resiliencia y capacidad organizativa como orquestadores de la gobernanza: al organizar una variedad de respuestas de salud pública y multisectoriales a la pandemia en asociación con otros actores intermedios, así como al participar en formas significativas de transferencia de gobernanza frente a sus Estados miembros. Estos logros son aún más impresionantes porque ocurrieron a pesar de un vacío de liderazgo y de los esfuerzos de líderes como Trump y Bolsonaro para debilitar a la oms y la ops.

Tal vez debido a la singular concentración de tantos estudiosos y estudiosas durante los últimos años sobre el regionalismo poshegemónico, sus formas interpresidenciales de gobernanza y sus manifestaciones institucionales, algunos de ellos y ellas llegaron a la conclusión prematura de que la cooperación regional se había derrumbado en toda América Latina y que había muy poca actividad de gobernanza organizada que trascendiera. Hemos descuidado el potencial de gobernanza de las organizaciones hemisféricas y regionales más formales, con sus propias secretarías per- 
manentes, su base en el derecho internacional público, así como sus propios presupuestos. Ciertamente no han faltado acciones decididas de su parte para luchar contra la Covid-19 y sus múltiples impactos, independientemente de si los líderes nacionales se llevan bien entre sí o no.

Este artículo es un llamado a un mayor intercambio fecundo de ideas entre el regionalismo comparativo, el institucionalismo neoliberal y los estudios de gobernanza global con el fin de pintar un panorama más completo de lo que está sucediendo en lo que atañe a la gobernanza regional de la pandemia de Covid-19 y otros problemas regionales. Por último, la moraleja de la historia que surge de estas páginas es que necesitamos encontrar maneras de limitar el daño potencial que los presidentes, individualmente o a través de sus interacciones, pueden causar a la gobernanza de la salud y otras áreas temáticas de gobernanza a través de su tendencia a un comportamiento impulsivo y antiinstitucional. Este análisis sugiere que el desafío consiste en cómo incrustar el interpresidencialismo en las redes intergubernamentales, transgubernamentales y transnacionales de acción y orquestación, a fin de maximizar los beneficios de la atención y la toma de decisiones interpresidenciales, compensando al mismo tiempo los peores impulsos de estas autoridades nacionales. En otras palabras, una tarea crucial es construir un interpresidencialismo en red, tanto en la teoría como en la práctica. Pero esa es una historia para la investigación futura.

Traducción de Rafael Segovia, GC IDiomas

\section{REFERENCIAS BIBLIOGRÁFICAS}

Аввотт, Kenneth W. y Benjamin faude, "Choosing Low-cost Institutions in Global Governance”, International Theory, 2020, pp. 1-30. Аввотт, Kenneth W., Philipp Genschel, Duncan Snidal y Bernhard ZANGL (eds.), International Organizations as Orchestrators, Cambridge, University Press, 2015. 
Аввотt, W. K., Philipp Genschel, Duncan Snidal y Bernhard ZANGL, "Two Logics of Indirect Governance: Delegation and Orchestration", British Journal of Political Science 46 (2015), pp. 719-729.

AgGaR Wal, Vinod K. (ed.), Institutional Designs for a Complex World: Bargaining, Linkages, and Nesting, Cornell, University Press, 1998. Alianza del Pacífico, AP, "Plan de Trabajo Frente al COVID-19", abril de 2020.

Andrus, Jon Kim, Ximena Aguilera, Otavio Oliva y Sylvain AlDIGHIERI, "Global Health Security and the International Health Regulations”, BMC Public Health, 10 (2010), pp. 1- 4.

Arrocha, P., y Fuente, J. R. de la, "Mexico's Initiative to Ensure Global Access to Medicines, Vaccines and Medical Equipment to Face COVID19", 29 de abril de 2020, https://www.justsecu rity.org/69916/mexicos-initiative-to-ensure-global-access-tomedicines-vaccines-and-medical-equipment-to-face-covid19/

Alter, Karen J., y Kal Rustiala, "The Rise of International Regime Complexity", Annual Review of Law and Social Science, 14 (2018), pp. 329-349.

Amaya, Ana B., y Philippe de Lombaerde, "Regional Cooperation is Essential to Combatting Health Emergencies in the Global South”, Globalization and Health, 17, 9, (2021), pp. 1-6.

Avery, Donald Howard, "The North American Plan for Avian and Pandemic Influenza: A Case Study of Regional Health Security in the $21^{\text {st }}$ Century", Global Health Governance 3, 2 (2010), pp. 1-25.

Banco de Desarrollo de América Latina, CAF, "COVID19: CAF makes USD 2.5 billion available for countries to protect their population and economies", Caracas, 23 de marzo de 2020, https://www.caf.com/en/currently/news/2020/03/covid19caf-makes-usd-25-billion-available-for-coun tries-to-protecttheir-population-and-economies/ (consulta del 24 de enero de 2021).

Banco de Desarrollo de América Latina, CAF, Proyectos, Caracas, https:/ / www.caf.com/es/proyectos/?kw=covid\&parent=0\&sd $=\&$ ed $=\&$ reset $=$ false (consulta del 24 de enero de 2021). 
Baracaldo Orjuela, David, y Jean-Marie Chenou, "Regionalism and Presidential Ideology in the Current Wave of Latin American Integration”, International Area Studies Review, 22 (2018), pp. 1-23.

BASILE, Gonzalo, La salud del proceso de integración regional: el caso Unasur salud ¿Soberanía o dependencia sanitaria?, República Dominicana, Flacso, 2019, pp. 3-30.

Bernal-Meza, Raúl, “¿Orden regulado por la anarquía? Asistimos al retorno del Leviatán”, Clarín, 19 de marzo, 2020.

BetTs, Alexander, "Regime Complexity and International Organizations: UNHCR as a Challenged Institution”, Global Governance, 19 (2013), pp. 69-81.

Biermann, Frank, Philipp Pattberg, Harro van Asselt y Fariborz Zelli, "The Fragmentation of Global Governance Architectures: A Framework for Analysis", Global Environmental Politics, 4 (2009), pp. 14-40.

Briceño-Ruiz, José e Isidro Morales, Post-Hegemonic Regionalism in the Americas: Toward a Pacific-Atlantic Divide?, Londres y Nueva York, Routledge, 2017.

Briceño-Ruiz, José, y Andrea Ribeiro Hoffmann, "The Crisis of Latin American Regionalism and Way Ahead", en Bettina De Souza Guilherme, Christian Ghymers, Stephany Griffith-Jones y Andrea Ribeiro Hoffmann (eds.), Financial Crisis Management and Democracy: Lessons from Europe and Latin America, Springer, 2021, pp. 281-293.

Bonilla Soria, Adrián y Lorena Herrera-Vinelli, "Celac como vehículo estratégico de relacionamiento de China hacia América Latina (2011-2018)", Revista CIDOB d'Afers Internacionals, 124 (2020), pp. 173-198.

Börzel, Tanya A. y Vera van Hüllen, "Towards a Global Script? Governance Transfer by Regional Organizations”, en Tanja A. Börzel y Vera van Hüllen (eds.) Governance Transfer by Regional Organizations, Londres, Palgrave Macmillan, 2015.

"Brasil abandona la Celac", El Universal, 16 de enero, 2020.

Buss, Paulo M. y Sebastián Toвar, "Health Diplomacy in the Political Process of Integration in Latin America and the Caribbean”, Oxford Research Encyclopedia of Global Public Health, 2018. 
Buss, Paulo M. y Sebastián Tobar, "Multilateralismo y Covid-19 en América Latina, Ensayos sobre la pandemia por Covid-19”, Revista Chilena de Salud Pública, (2020), pp. 123-135.

Buss, Paulo M. y Sebastián ToBar, "Covid-19 and Opportunities for International Cooperation in health”, Cadernos de Sáude Pública Reports in Public Health, 36, 4 (2020), pp. 1-3.

Comisión Económica de América Latina, Cepal, "Costa Rica presenta propuesta de Fondo para Aliviar la Economía Covid-19”, 25 de septiembre 2020.

Comunidad del Caribe, Caricom, "News Feature: Caribbean Community Successfully Keeps Low Covid-19 Infection Rates", Caricom, 13 de julio de 2020.

COOPER, Andrew F. y Richard Stubbs, "Contending Regionalisms: Hubs and Challengers in the Americas and the Asia-Pacific", The Pacific Review, 30 (2017), pp. 615-632.

Coronado Martínez, María Esther, "The Mexican Experience of the Napapi Revision Process". Contexto Internacional, 38, 1 (2016), pp. 203-239.

Covarrubias, Ana, “¿Unidad en la diversidad? La crisis del multilateralismo en América Latina”, El País (secc. Opinión), 12 de marzo de 2020.

Cueto, Marcos, El valor de la salud: Historia de la Organización Panamericana de la Salud, Washington, D.C., Organización Panamericana de la Salud, 2004.

DABÈnE, Olivier, "La cuarta ola de regionalismo", en Carlos Quenan, Sébastien Velut y Eric Jourcin (coords.), Los desafios del desarrollo en América Latina, París, Institut des Amériques, 2014, pp. 64-95.

Dubé, Sébastien, "A Supposed Fifth Wave of Latin American Regionalism and Human Needs", Regions and Cohesion, 10, 3 (2020), pp. 58-71.

Fletcher-Lartey, Stephanie, Lisa Indar, Tamu Davidson, Gabriel González Escobar y Joy St. John, "Protecting Health Security in the Caribbean: A Coordinated Regional Response to the Novel Coronavirus Disease (Covid-19) and Other Global Public Health Threats", International Public Health Journal, 12, 1 (2020), pp. 33-45. 
Fonplata, "Apoyo de Fonplataen respuesta al Covid-19 para los países miembros", Fonplata: Banco de Desarrollo, https://www. fonplata.org/es/noticias/23-09-2020/apoyo-de-fonplata-enrespuesta-al-covid-19-para-los-paises-miembros

Foro para el Progreso de América del Sur, Prosur, "Informe de Gestión Prosur", marzo de 2019-diciembre de 2020.

Frenkel, Alejandro, "El Mercosur ante la Covid-19: de la disputa comercial a la amenaza sanitaria”, Análisis Carolina, 40/2020, 24 de junio 2020.

García, Patricia J., et al, "Covid-19 Response in Latin America", The American Journal of Tropical Medicine and Hygiene, 103 (2020), pp. 1765-1772.

Gardini, Gian Luca, "Covid-19, la movilización y solidaridad de la UE, y el regionalismo comparado", en Gian Luca Gardini (coord.), El mundo antes y después de la Covid-19, Salamanca, Instituto Europeo de Estudios Internacionales, 2020, pp. 124-128.

Global Health Security Index, 2019, https://www.ghsindex.org/ (consulta del 24 de enero de 2021).

Gobierno de España, La Moncloa, "President of the Government chairs the High-Level Conference entitled 'United in providing a response for America and the Caribbean to Covid-19'”, 24 de junio de 2020, https://www.lamoncloa.gob.es/lang/ en/presidente/news/Paginas/2020/20200624la-conference. aspx (consulta del 23 de enero de 2021).

Gobierno de México, Secretaría de Relaciones Exteriores, SRE, "México Impulsa en Naciones Unidas propuesta para garantizar el acceso a medicamentos, vacunas y equipo médico para hacer frente al Covid-19”, 17 de abril de 2020, https://www. gob.mx/sre/prensa/mexico-impulsa-en-naciones-unidas-propuesta-para-garantizar-el-acceso-a-medicamentos-vacunas-yequipo-medico-para-hacer-frente-al-covid-19 (consulta del 22 de enero de 2021).

Gobierno de México, Secretaría de Relaciones Exteriores, SRE, "The Foreign Ministry Stregthens North American Cooperation on COVID-19 Pandemic", SRE, 12 de mayo de 2020.

Hanrieder, Tine, "WHO Orchestrates?", en Kenneth W. Abbott., Philipp Genschel, Duncan Snidal y Bernhard Zangl (eds.), In- 
ternational Organizations as Orchestrators, Cambridge, University Press, 2015, pp. 191-213.

Hawkins, Darren G., David L. Lake, Daniel L. Nielsen y Michael J. Tierney (eds.), Delegation and Agency in International Organizations, Cambridge, University Press, 2006.

Hirst, Mónica y Bernabé Malacalza, “¿Podrá reinventarse el multilateralismo? El orden internacional y el coronavirus", Nueva Sociedad, 287 (2020), pp. 35-48.

Herrero, María Belén y Diana Tussie, "Unasur Health: A Quiet Revolution in Health Diplomacy in South America”, Global Social Policy 15, 3 (2015), pp. 261-277.

Hoffman, Steven J., "The evolution, etiology and eventualities of the global health security regime", Health Policy and Planning, 25 (2010), pp. 510-522.

Banco Interamericano de Desarrollo, "Inter-American Development Bank", https://www.iadb.org/en/projects-search?count $r y=\&$ sector $=\&$ status $=\&$ query $=$ COVID, consultado el 24 de enero, 2021.

Ikenberry, John, "The Future of International Leadership”, Political Science Quarterly, 111 (1996), pp. 358-402.

Jarque, Carlos M., María Salvadora Ortiz y Carlos Quenan (eds.), América Latina y la Diplomacia de Cumbres, Ciudad de México, Secretaría General Iberoamericana, 2010.

King, Arlene, Jon Kim Andrus y J. Peter Figueroa, "Financial Crisis at PAHO in the Time of Covid-19: A Call for Action", The Lancet, 396 (2020), p. 96.

Kirkpatrick, David D. y José María León Cabrera, "How Trump and Bolsonaro Broke Latin America's Covid-19 Defenses", The Nueva York Times (secc. World), 27 de octubre de 2020.

Lakoff, Andrew, "Two Regimes of Global Health", Humanity: An International Journal of Human Rights Humanitarianism and Development, 1 (2010), pp. 59-79.

Legler, Thomas, "Post-hegemonic Regionalism and Sovereignty in Latin America: Optimists, Skeptics, and an Emerging Research Agenda", Contexto Internacional, 35 (2013), pp. 325-352.

Legler, Thomas y Ornela Garelli-Ríos, "La protección de la democracia ante la crisis venezolana: los límites del nexo hemis- 
férico-regional de gobernanza en las Américas", Pensamiento Propio, 2018, 47, pp. 159-188.

Legler, Thomas y Detlef Nolte, "Venezuela: la protección regional multilateral de la democracia”, Foreign Affairs Latinoamérica, 2, 2019, pp. 43-41.

Mace, Gordon, Jean Philippe Thérien, Diana Tussie y Olivier DABÈnE (eds.), Summits and Regional Governance: The Americas in comparative perspective, Nueva York, Routledge, 2016.

Malamud, Andrew, "Presidential Diplomacy and the Institutional Underpinnings of Mercosur: An Empirical Examination”, Latin American Review (40), 2005, pp. 138-164.

Malamud, Andrés, "Presidentialist Decision Making in Latin American Foreign Policy: Examples from Regional Integration Processes", en Jorge I. Domínguez y Ana Covarrubias (eds.), Routledge Handbook of Latin America in the World, Routledge, 2014, pp. 124-136.

Malamud, Carlos, "Coordinación regional frente al Covid-19 en América Latina”, Elcano Royal Institute, 3 de junio de 2020.

Malamud, Carlos, "Latinoamérica al son de la Covid-19", La Verdad, 26 de julio de 2020.

Malamud, C. y R. NúÑEz, “AMlo y Bolsonaro ante el coronavirus: tan distintos y, sin embargo, tan iguales”, Elcano Royal Institute, 26 de marzo de 2020.

Mercado Común del Sur, Mercosur, "Declaración de los presidentes del Mercosur sobre coordinación regional para la contención y mitigación del coronavirus y su impacto”, 18 de marzo de 2020.

Mercado Común del Sur, Mercosur, "Más fondos del Mercosur para combatir la Covid-19”, 6 de octubre de 2020.

"México subestima la magnitud de la epidemia de Covid-19: oms", Infobae (secc. México), 21 de agosto de 2020.

Morse, Julia C. y Robert O. Keohane, "Contested Multilateralism”, Review of International Organizations, 9 (2014), pp. 385-412.

Naciones Unidas, Asamblea General, "Resolution adopted by the General Assembly on 20 abril 2020, 74/24”, 21 de abril, 2020.

Naciones Unidas, un News, "La oms alerta de un problema serio en México por el aumento de casos y muertes de Covid-19", 30 de noviembre de 2020. 
Nolte, Detlef, "Costs and Benefits of Overlapping Regional Organizations in Latin America: The Case of the OAS and UNASUR”, Latin American Politics and Society, 60, 1 (2018), pp. 128-153. Nolte, Detlef y Weiffen, Brigitte (eds.), Regionalism Under Stress: Europe and Latin America in Comparative Perspective, Londres y Nueva York, Routledge, 2020.

Oré, Diego, "Mexico Says China Plans \$1 Billion Loan to Ease Latam Access to Virus Vaccine", Reuters, 22 de julio, 2020.

Organización Mundial de la Salud, oms, International Health Regulations, wHO Press, 2. ${ }^{\text {a }}$ ed., 2005.

Organización Mundial de la Salud, oms/Organización Panamericana de la Salud, ops, "Reunión de Ministros de Salud de la Unasur”, 8 de agosto, 2009.

Organización Panamericana de la Salud, ops, "Geo-Hub Covid-19Information System for the Region of the Americas", https:// paho-covid19-response-who.hub.arcgis.com/ (consulta del 23 de enero de 2020).

Organización Panamericana de la Salud, ops, "Response to Covid-19 Outbreak in the Region of the Americas", PAHO, versión 3, 28 de agosto de 2020.

Organización Panamericana de la Salud, ops, "PAHO Raises \$263 Million in 2020 to Fight Covid-19 in Americas", PAHo, 12 de enero de 2021.

Palestini, Stefano, "Orchestrating Regionalism: The Interamerican Development Bank and the Central American Electric System”, Review of Policy Research, 2020.

Parthenay, Kevin, "Why Central American Regionalism Never Ends Dying: A Historical Exploration of Regional Resilience", en José Briceño-Ruiz y Andrés Rivarola Puntigliano (eds.), Regionalism in Latin America: Agents, Systems, and Resilience, Oxon y Nueva York, Routledge, 2020, pp. 31-49.

Quiliconi, Cintia, "The Crossroads of Latin American Regionalism: A Cycle Shift or a Return to Open Regionalism?", Linea Sur: Strategic agenda and Integration, 14 (2018), pp. 140-151.

Riggirozzi, Pia, "Regionalism, Activism, and Rights: New Opportunities for Health Diplomacy in South America", Review of International Studies 41, 2 (2015), pp. 407-428. 
Riggirozzi, Pia, "Coronavirus y el desafío para la gobernanza regional en América Latina”, Análisis Carolina, 12, 2020.

Riggirozzi, Pia y Tussie, Diana (eds.) The Rise of Post-hegemonic Regionalism: The Case of Latin America, Springer, 2012.

Ríos Sierra, Jerónimo, "La inexistente respuesta regional a la Covid-19 en América Latina”, Geopolítica(s) Revista de Estudios sobre Espacio y Poder, 11 (2020), pp. 209-222.

Ríos Sierra, Jerónimo, "Una aproximación (geo)política a la crisis de la Covid-19 en América Latina", Journal of Latin American Geography, 19, 3 (2020), pp. 194-201.

Rodrigues, Gilberto M.A. y Alberto Kleiman, "Covid-19: ¿una nueva oportunidad para el multilateralismo?", Foreign Affairs Latinoamérica, 3 (2020), pp. 36-43.

Roger, Charles B., The Origins of Informality: Why the Legal Foundations of Global Governance are Shifting, and Why It Matters, Nueva York, Oxford University Press, 2020.

Rojas Aravena, Francisco (ed.), Globalización, América Latina y la Diplomacia de las Cumbres, Chile, Flasco-Chile, 1998.

Secretaría General Iberoamericana, "Socios frente al Covid-19, convocatoria para el fortalecimiento de la Cooperación SurSur en Iberoamérica", 6 de agosto de 2020, https:/ / www.segib. $\mathrm{org} /$ call/socios-frente-al-covid-19-convocatoria-para-el-fortalecimiento-de-la-cooperacion-sur-sur-en-iberoamerica/.

Sistema de Integración Centroamericana, Sica, "Observatorio Regional Sica-Covid 19”, https://www.sica.int/coronavirus/observatorioSICACOVID19\#, consultado el 23 de enero, 2021.

Sistema de Integración Centroamericana, Sica, "Plan de Contingencia Regional: Orientando a complementar los esfuerzos nacionales para la prevención, contención y tratamiento de la Covid-19", Sica, 2020.

Spyros, Blavoukos y Dimitris Bourantonis, "Nested Institutions", en Rafael Biermann y Joachim A. Koops (eds.), Palgrave Handbook of Inter-Organizational Relations in World Politics, Londres, Palgrave Macmillan, 2017, pp. 303-315.

Stuenkel, Oliver, "The Peril of a Rudderless Continent", Americas Quarterly, 29 de octubre de 2020. 
Trinidade Lima, Nísia, Paulo Marchiori Buss y Rômulo PaesSousa, "Covid-19 Pandemic: A Health and Humanitarian Crisis”, Cuadernos de Saúde Pública, 2020, núm. 7, pp. 2-3.

Trump, Donald J., Letter addressed to the Director-General of the World Health Organization, 18 de mayo de 2020.

Vabulas, Felicity y Duncan Snidal, "Organization Without Delegation: Informal Intergovernmental Organizations (IIGOs) and the Spectrum of Intergovernmental Arrangements", Review of International Organizations, 8 (2013), pp. 193-220.

VAn Klaveren, Alberto, "La crisis del multilateralismo y América Latina”, Análisis Carolina 10/2020, 10 de marzo de 2020.

Wier, Lorna, "Inventing Global Health Security, 1994-2005", en Simon Rushton y Jeremy Youde (eds.), Routledge Handbook of Global Health Security, Londres y Nueva York, Routledge Taylor y Francis Group, 2014.

Weiss, Thomas G., Global Governance: What? Why? Whither?, Cambridge, Polity, 2013.

Whitehead, Laurence y Alexandra Barahona De Brito, "Las Cumbres Mundiales y sus Versiones Latinoamericanas: ¿Haciendo una montaña de un grano de arena?”, América Latina Hoy, 40 (2005), pp.15-27. 
